\title{
Vibration Response of Combine Harvester Chassis Undergoing Multisource Excitation Force Distribution
}

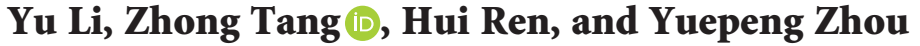 \\ Key Laboratory of Modern Agricultural Equipment and Technology of Ministry of Education, Jiangsu University, \\ Zhenjiang 212013, Jiangsu, China \\ Correspondence should be addressed to Zhong Tang; tangzhong2012@126.com
}

Received 3 September 2020; Revised 6 December 2020; Accepted 15 January 2021; Published 29 January 2021

Academic Editor: Ioannis Kostavelis

Copyright () $2021 \mathrm{Yu} \mathrm{Li}$ et al. This is an open access article distributed under the Creative Commons Attribution License, which permits unrestricted use, distribution, and reproduction in any medium, provided the original work is properly cited.

When a combine harvester is harvesting in field under complicated conditions, vibration characteristics of the chassis frame under the excitation of multiple sources are complex and changeable. In order to analyze the vibration characteristics of the chassis frame of the combine harvester under complex working conditions and multisource excitation, this paper carried out three-dimensional modeling and static calculation of the chassis frame of the combine harvester. On this basis, the experimental modal analysis was carried out on the designed chassis frame, and finally, the vibration response under multiple excitations and complex working conditions was tested and analyzed in the field. Results showed that when the combine harvester was fully loaded, the maximum bending moment was at the load-bearing beam under the grain box. The maximum bending moment was $2298.08 \mathrm{~N} / \mathrm{m}$, and it was located at the cross section of the left end of the bearing beam at $1.61 \mathrm{~m}$. When the components of the whole machine were working, the vibration of the chassis frame at the rear right was the most intense. The horizontal vibration of the threshing drum, the reciprocating motion generated by the vibrating screen, and the vertical vibration generated by the engine were the main vibration sources of the combine harvester in the three directions of $X, Y$, and $Z$. With the ilncrease of engine speed, the excitation capacity of each working component connected to the engine on the whole machine increased. The results of this paper provide experimental basis for the research on the vibration characteristics of the chassis frame of the rice combine harvester under multisource excitation and also provide a reference for the further improvement of the chassis frame of the combine harvester.

\section{Introduction}

With the development of science and technology and the gradual improvement of mechanization, rice harvesting has basically achieved full mechanization [1]. The crawler rice combine harvester is a complex large-scale agricultural harvesting machine that integrates mechanical functions such as harvesting, threshing, separation, and sorting [2-4]. During the field harvesting operation in complex working conditions, the vibration characteristics of the chassis frame under the excitation of multiple sources are complex and changeable, which will affect the reliability and operation safety of the whole machine field harvesting [5-7]. In addition, when the combine harvester is working, there are generally problems such as large vibration of the whole machine, easily damaged parts, and low reliability of the whole machine, which seriously affect the harvest efficiency and the physical and mental health of the driver [8-10].

As the main bearing part of the combine harvester, the chassis frame is responsible for connecting the working parts and walking devices of the whole machine. Whether the designed chassis frame can carry the mass of these working components will directly affect the safety and reliability of the whole machine [11]. The optimization method of the chassis frame is mainly aimed at its carrying capacity, and its statics are simulated and analyzed by software. On this basis, the larger and weaker parts are found to be further improved. $\mathrm{Hu}$ and $\mathrm{Du}$ took the corn combine harvester as the object and analyzed the stress distribution and displacement of the chassis frame under the conditions of no load or full load through finite element software [12]. Not only in the field of agricultural machinery but also in the field of 
automobiles there is a need to optimize the chassis frame. Vijaykumar and Patel conducted structural analysis of the chassis frame of the car through finite element software and further optimized its quality under the premise of ensuring the working reliability of the rack, thereby improving the working performance of the vehicle [13]. Nagaraju et al. calculated the load of the mobile chassis of a car and conducted a static analysis through ANSYS to check its load capacity [14]. Tang et al. analyzed the structural characteristics and bearing capacity of crawler chassis based on the finite element model and designed a new type of crawler chassis joystick to improve the stability of the whole machine under high load. These are all theoretical verification and analysis through finite element software [15]. Due to the influence of different boundary conditions and different calculation methods, the calculation results are also different from the actual ones.

Due to the harsh working conditions of the combine harvester and the multiple components working at the same time during the field harvesting operation, even if the static design requirements are met, it is difficult to ensure the stability of the chassis frame during operation. When a working component of the combine harvester resonates with the chassis frame, it will greatly weaken the carrying capacity of the frame causing severe vibration of the chassis frame. As a result, it will crack and fracture, which has a great impact on the reliability of the whole machine. Analysis of the inherent characteristics of the chassis frame of the combine harvester is mainly divided into two types, one is the theoretical modal analysis and the other is the experimental modal analysis. Theoretical modal analysis uses modal analysis software to perform simulation calculations, which is simple and convenient, but the calculation results are somewhat different from the actual ones. The test mode is closer to the actual situation, but it needs to be manufactured, and then, the test process is relatively cumbersome and random. Chen et al. proposed a method for online evaluation of the dynamic performance of the chassis of heavy dump trucks based on a new stochastic subspace identification (SSI) method. By reducing the noise and nonstationary content in the vibration signal from the frame, accurate modal characteristics can be obtained to actually evaluate the dynamic behavior of the frame [16]. Jiang et al. analyzed the modal and static characteristics of rapeseed windrowers through finite element analysis [17]. The natural frequency of the frame was adjusted to avoid resonance, and a finite element static analysis was performed on the optimized frame. According to the simulation results, the frame structure of the rape windrower was optimized, and the working reliability of the whole machine was improved. Ganesan and Panneerselvam took the heavy vehicle chassis frame as the research object and solved it by aligning the natural frequency [18]. In addition, the frequency component of road excitation was analyzed. By placing reinforcement plates of different shapes around the chassis frame, the natural frequency of bending and torsion was moved above the excitation frequency of the road, so that it avoided the resonance zone and improved its ability to resist bending and torsion. As a result, stability of the whole machine was improved. In addition to considering the case of resonance, when there are multiple excitation sources on the chassis frame, vibration superposition will occur, which will increase the vibration of the whole machine and shorten the working life of the machine. Therefore, it is also very important to study the vibration characteristics under multisource excitation.

When the combine harvester was working in field, due to the excitation effect of the road surface and the simultaneous action of multiple working components, the entire frame would show significant vibration. The low reliability of combine harvesters is directly related to their severe vibration. Relevant data showed that $80 \%$ of the mechanical structure damage was fatigue damage, and $75 \%$ of the mechanical structure damage was related to vibration [19-21]. Severe vibration will reduce the reliability of the combine harvester, leading to the chassis frame more prone to fatigue damage and ultimately affect the working efficiency of the whole machine [22-24]. The combine harvester as a multifunctional machine has multiple working components on it, which causes the phenomenon of multisource excitation. Strong and continuous vibration and simultaneous excitation of multiple working components is an important cause of fatigue damage to the combine harvester frame. Therefore, it is particularly important to study the multisource excitation characteristics of the combine. The research on multisource excitation problems is mainly concentrated in the field of vehicles and ships, and there is very little research on fitting the multisource excitation characteristics of harvesters. Fang and Zhang took electric vehicles as the research object and conducted numerical analysis and experiments on their vibration and acoustic behavior [25]. Through the forced response analysis of the finite element mesh of the shell, the effect of various excitations on the NVH performance of the electric power transmission system was studied. Xie et al. studied the vibration response of ships and other structures under multipoint complex load excitation [26]. Taking the excitation motor installed on the base panel as the excitation source, the vibration source and the base panel were connected at multiple points through a force sensor, and the vibration response under multipoint excitation was simulated and experimentally studied. Chen et al. took the rice combine harvester as the research object [27]. Based on the multisource excitation of the combine harvester, the chassis rack and the thresher were assembled into a complete combine harvesting rack. The vibration response of the frame of the combine under multisource excitation was derived, and the dynamic model of the frame of the combine with a 7-degree-of-freedom rigid body was established. On this basis, the simulation analysis of the excitation parameters and vibration response of the dynamic model was developed in MATLAB. The abovementioned research studies on the vibration characteristics of the system under multiple excitations were carried out under theoretical conditions. For the combine harvester system with complex and diverse working conditions and multiple excitations coexisting, the simulated state often deviates greatly from the actual one. Therefore, the research 
on the vibration characteristics of multisource excitation under actual working conditions is particularly important.

This paper took the crawler rice combine harvester as the research object. According to the installation position and physical characteristics of each working component, the chassis frame was $3 \mathrm{D}$ modeled and statically calculated. On this basis, the experimental modal analysis of the designed combine harvester chassis frame was carried out to study the resonance of the frame and the excitation source. Furthermore, the field tests were carried out under the premise of further optimization of the structure, and the vibration characteristics of the chassis frame were measured and studied under multiple working conditions. Finally, its vibration response under multiple working conditions and multiple excitations was analyzed. This paper systematically studies the vibration characteristics of the chassis frame of the crawler combine harvester under multisource excitation, which provided important experimental basis and results for the vibration characteristics of the chassis frame of the rice combine harvester under multisource excitation. At the same time, it provided reference for the further optimization and improvement of the chassis frame of the combine harvester.

\section{Material and Methods}

\subsection{Chassis Frame Structure Load and Stress State}

2.1.1. Overall Stress State of the Chassis Frame. The chassis frame of the combine harvester mainly plays a load-bearing role, and the loads it receives mainly come from 8 aspects, including the grain box, the cab, the engine, the fuel tank, the cylinder, the threshing drum, and the accumulator. The installation position of each working component on the combine harvester is shown in Figure 1.

Taking the components carried on the chassis frame as the analysis standard, the stress situation of each component of the chassis frame was analyzed. First, we determine the specific stress of the beam and then mark the stress portion on the crawler chassis based on the installation position of each working component of the combine under the assembly of the whole machine. Specifically, it included the grain box stress surface, the cab stress surface, the engine stress surface, the fuel tank stress surface, the cylinder stress surface, the threshing drum stress surface, and the accumulator stress surface. The main component parameters are shown in Table 1.

We simplify the bearing and load on the chassis frame of the combine harvester (among them, the welding place was simplified as a fixed support) and get the beam calculation diagram. After simplification, the analyzed beams were all statically determinate beams, including simply supported beams, overhang beams, and cantilever beams $[28,29]$. The schematic diagram of the actual force application position of each component to the chassis frame is shown in Figure 2.

According to the balance equation, the bearing restraint force of the statically determinate beam under load was obtained. Therefore, the external forces on the beam were all known quantities, and the internal forces on each section can be further studied. Through the calculations, the shear force $F_{s}$ and bending moment $M$ on each cross section can be obtained [30]. The signs of the shear force and bending moment are shown in Figure 3.

At the same time, the position of the cross section on the beam was expressed as the abscissa $x$, so the shear force and bending moment on each section can be expressed as a function of $x$. The shear force equation and bending moment equation of the beam are shown in the following equations:

$$
\begin{aligned}
& F_{s}=F_{s}(x), \\
& M=M(x),
\end{aligned}
$$

where $F_{s}$ and $M$ are the shear force and bending moment of a cross section of the bearing beam, respectively.

The abscissa $x$ parallel to the beam axis represented the position of the cross section, and the ordinate represented the shear force or bending moment on the corresponding section. Shear graphs and bending moment graphs can be drawn, through which the position of the dangerous section and the corresponding value can be clearly seen.

\subsubsection{Analysis of the Main Components Applying Load to the Bearing Beam}

(1) The effect of the grain box on the chassis frame is shown in Figure 2. The cross section of the beam was $50 \times 50 \mathrm{~mm}$. The load concentration $q=15490(\mathrm{~N} / \mathrm{m})$ can be obtained from the bearing area and full-load pressure. The no. (1) beam was divided into three sections according to its stress conditions. Section A-B did not directly bear the load, and the uniformly distributed load was mainly distributed in sections B-C. Therefore, the calculation of the establishment and bending moment of beam no. (1) needed to be performed separately. The stress conditions of beams no. (2) and (3) were the same, and there were also different situations of multiend stress. The load conditions of each beam carrying the grain box are shown in Table 2.

(2) The load of the chassis frame on the cab is shown in Figure 2, and the cross section of the beam was $50 \times 50 \mathrm{~mm}$. There were four beams supporting the cab, numbered (4), (5), (6), and (7). Then, the no. (5) beam was a statically indeterminate continuous beam, and the no. (4), (6), and (7) beams were statically determined simply supported beams. The load concentration $q=750(\mathrm{~N} / \mathrm{m})$ can be obtained from the load-bearing area and full-load pressure. The load-bearing condition of each beam is shown in Table 2.

(3) The force situation of the engine installation position is shown in Figure 2. Two beams were mainly stressed on the frame where the engine was installed. The stress location and stress area of the two beams were the same, so only one beam needed to be analyzed. Its main load-bearing position was in the B-C and D-E beam. From the load-bearing area and full- 


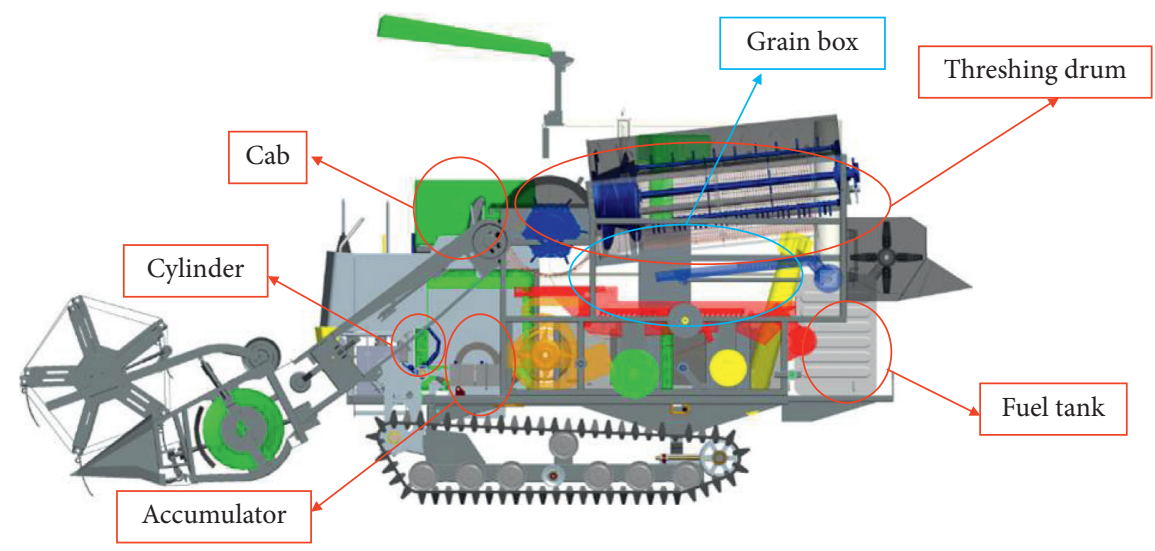

FIgURE 1: Schematic diagram of the location of each working component.

TABLE 1: Parameters of the main components of the combine harvester.

\begin{tabular}{lccccccc}
\hline Main components & Grain box & Cab & Engine & Fuel tank & Cylinder & Threshing drum & Accumulator \\
\hline Quality $(\mathrm{kg})$ & 1771 & 265 & 300 & 85 & 359.4 & 1260 & 50 \\
Bearing area $\left(\mathrm{m}^{2}\right)$ & 0.056 & 0.1760 & 0.0264 & 0.1350 & 0.0142 & 0.1585 & 0.0154 \\
Full-load pressure $(\mathrm{MPa})$ & 0.309 & 0.0150 & 0.1040 & 0.0617 & 0.2480 & 0.0779 & 0.0319 \\
Allowable load $(\mathrm{N})$ & 20826.8 & 3116.4 & 3528 & 999.6 & 4226.88 & 14817.6 & 588 \\
\hline
\end{tabular}

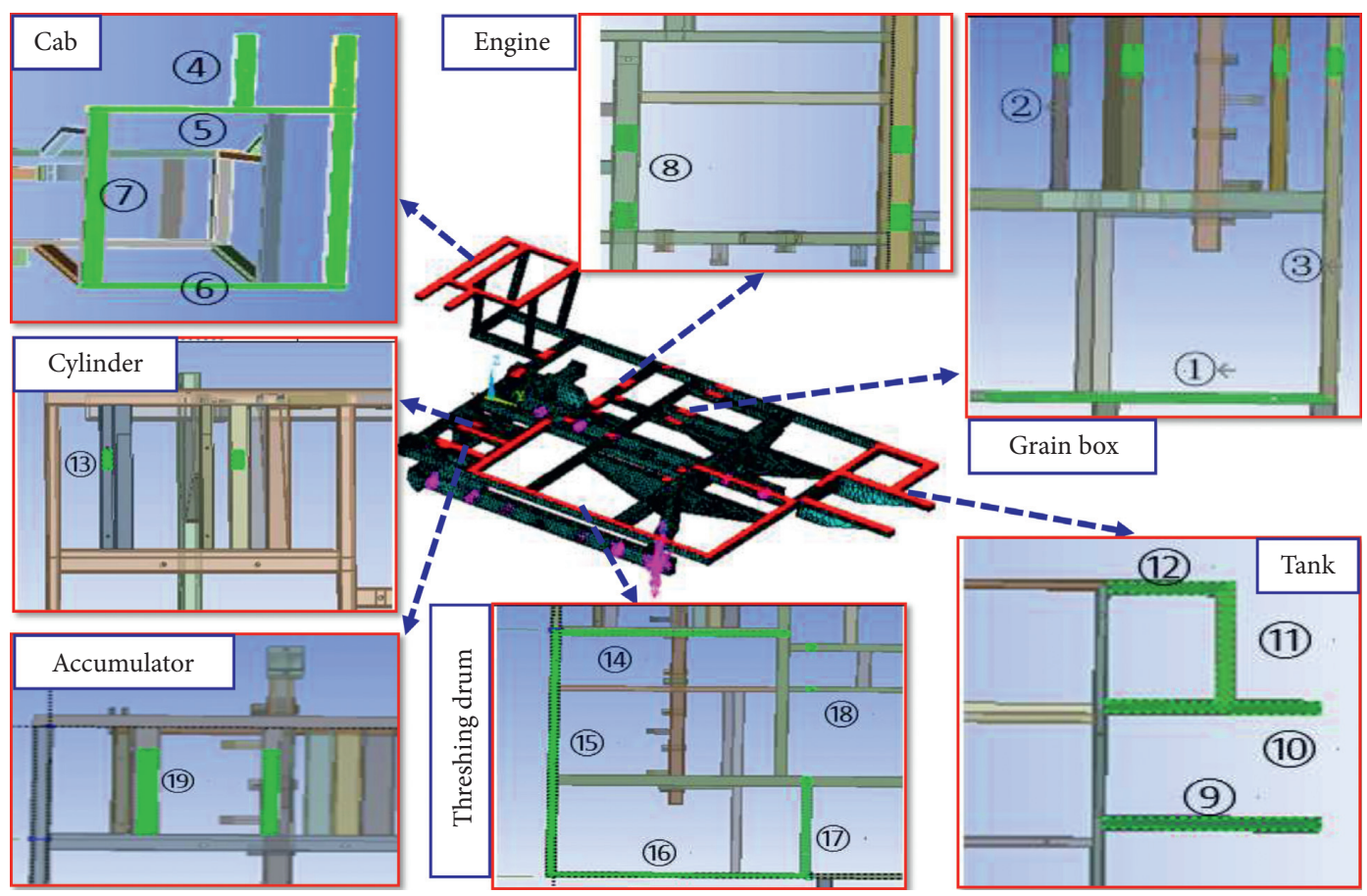

Figure 2: Schematic diagram of the stressed surface on the chassis of the crawler walking chassis.

$(+)$

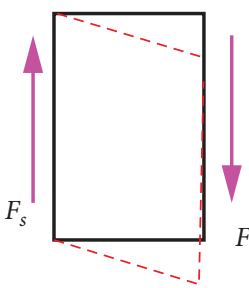

$(-)$

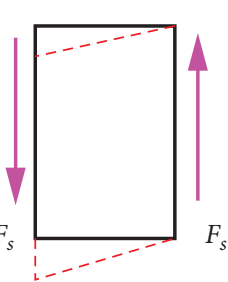

(a)
$(+)$

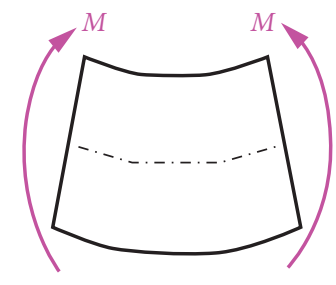

$(-)$

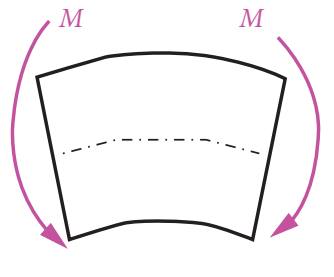

(b)

FIGURE 3: Symbol requirements for shear and bending moments in calculations. (a) Symbol requirements for shear. (b) Symbol requirements for bending moments. 
TABLe 2: Beams no. (1) (8) stress situation.

\begin{tabular}{|c|c|c|c|c|c|c|c|}
\hline Position & $\begin{array}{c}\text { Beam } \\
\text { number }\end{array}$ & Type & Segmentation & $\begin{array}{l}\text { Length } \\
\text { (m) }\end{array}$ & $\begin{array}{l}\text { Total length } \\
L(\mathrm{~m})\end{array}$ & Pivot & $\begin{array}{l}\text { Uniform load } \\
(\mathrm{N} / \mathrm{m})\end{array}$ \\
\hline \multirow{6}{*}{$\begin{array}{l}\text { Grain } \\
\text { box }\end{array}$} & (1) & Simply supported beam & 2 segments $(A-B ; B-C)$ & $\begin{array}{l}\text { A-B: } 1.51 \\
\text { B-C: } 0.64\end{array}$ & 2.15 & 2: A, C & B-C: 15490 \\
\hline & & & & A-B: 0.45 & & & \\
\hline & (2) & Simply supported beam & 3 segments (A-B; B-C; C-D) & B-C: 0.12 & 0.65 & 2: A, D & B-C: 15490 \\
\hline & & & & C-D: 0.08 & & & \\
\hline & & & & A-B: 0.45 & & & \\
\hline & (3) & Simply supported beam & 3 segments (A-B; B-C; C-D) & $\begin{array}{l}\text { B-C: } 0.12 \\
\text { C-D: } 0.08\end{array}$ & 0.65 & 2: A, D & B-C: 15490 \\
\hline \multirow{4}{*}{$\mathrm{Cab}$} & (4) & Simply supported beam & 1 segment $(A-B)$ & $\begin{array}{l}\text { A-B: } 0.31 \\
\text { A-B: }\end{array}$ & 0.31 & 2: A, B & A-B: 750 \\
\hline & (5) & $\begin{array}{l}\text { Statically indeterminate } \\
\text { continuous beam }\end{array}$ & 2 segments $(A-B ; B-C)$ & $\begin{array}{c}0.265 \\
\text { B-C: } \\
0.335\end{array}$ & 0.60 & $\begin{array}{l}\text { 3: A, B, } \\
\text { C }\end{array}$ & $\begin{array}{l}\text { A-B: } 750 \\
\text { B-C: } 750\end{array}$ \\
\hline & (6) & Simply supported beam & 1 segment $(A-B)$ & A-B: 0.60 & 0.60 & 2: A, B & A-B: 750 \\
\hline & (7) & Simply supported beam & 1 segment $(A-B)$ & A-B: 0.73 & 0.73 & 2: A, B & A-B: 750 \\
\hline Engine & (8) & Simply supported beam & $\begin{array}{c}5 \text { segments (A-B; B-C; C-D; } \\
\text { D-E; E-F) }\end{array}$ & $\begin{array}{l}\text { A-B: } 1.35 \\
\text { B-C: } 0.12 \\
\text { C-D: } 0.23 \\
\text { D-E: } 0.12 \\
\text { E-F: } 0.29\end{array}$ & 2.11 & 2: A,B & $\begin{array}{l}\text { B-C: } 5720 \\
\text { D-E: } 5720\end{array}$ \\
\hline
\end{tabular}

load pressure given in Table 1 , the load concentration $q=5720(\mathrm{~N} / \mathrm{m})$ can be obtained. The beam cross section was $40 \times 60 \mathrm{~mm}$. The load-bearing conditions are shown in Table 2.

(4) There were four main load-bearing beams of the fuel tank, and the schematic diagram of its force is shown in Figure 2. From the parameters of the load-bearing area and the pressure at full load in Table 1, the load concentration of the load-bearing beam of the oil tank can be obtained as $q=3085 \mathrm{~N} / \mathrm{m}$, and the simplified calculation diagram is shown in Figure 4(a). Both no. (9) and (10) beams were cantilever beams, and their analysis methods are similar. The difference was that there was still a fixed load on beam no. (10), so the calculation method of beam no. (10) was slightly different from that of beams no. (9), (11), and (12) beams were simply supported beams, and their analysis methods were the same as before.

(5) The force of the cylinder is shown in Figure 2. The cross section of the beam was $40 \times 40 \mathrm{~mm}$. There were two main beams, and the position and area of the two beams were the same. Only a part of each beam received a uniform load of $0.0024 \mathrm{~m}^{2}$. From the parameters of the bearing area of the cylinder and the full-load pressure given in Table 1 , the load concentration $q=12400(\mathrm{~N} / \mathrm{m})$ can be obtained. The simplified calculation diagram is shown in Figure 4(b).

(6) The force of the accumulator was shown in Figure 2. The cross section of the beam was $40 \times 40 \mathrm{~mm}$. Its bearing method was the same as that of the cylinder, so only one beam was needed to be analyzed. From the parameters of the accumulator bearing area and full-load pressure given in Table 1, the load concentration $q=701.8(\mathrm{~N} / \mathrm{m})$ can be obtained. The calculation diagram is shown in Figure 4(b).

(7) There were four main load-bearing beams of the threshing drum. In addition to this, there were two auxiliary supporting beams. The schematic diagram of the force is shown in Figure 2. No. (14), (16), and (17) beams were simply supported beams, all of which were subjected to uniformly distributed loads covering the entire beam. Their restraint positions and methods were the same; the difference was that their sizes were inconsistent; beam no. (15) was a statically indeterminate continuous beam, which can reduce the maximum bending moment; beam no. (18) was also a simply supported beam, which was partially distributed. The calculation method of the shear force and bending moment of beam no. (14), (16), and (17) was the same as the calculation method of the previously simply supported beams. From the parameters of the load-bearing area of the threshing drum and the pressure at full load in Table 1, the load concentration of the load-bearing beam can be obtained as $q=3895 \mathrm{~N} / \mathrm{m}$.

2.2. Design Parameters of the Chassis Frame. The chassis frame is composed of four main beams and five main longitudinal beams and auxiliary beams supporting other components. It is mainly determined according to the layout of each assembly of the combine harvester and the quality of each component of the entire combine harvester. The chassis frame was welded with square and rectangular tubes of different specifications such as $30 \times 30 \mathrm{~mm}, 40 \times 40 \mathrm{~mm}$, and $50 \times 50 \mathrm{~mm}$. Its thickness had 4 specifications of $2 \mathrm{~mm}, 3 \mathrm{~mm}, 4 \mathrm{~mm}$, and $6 \mathrm{~mm}$ and was fixed and reinforced with a connecting plate. The 


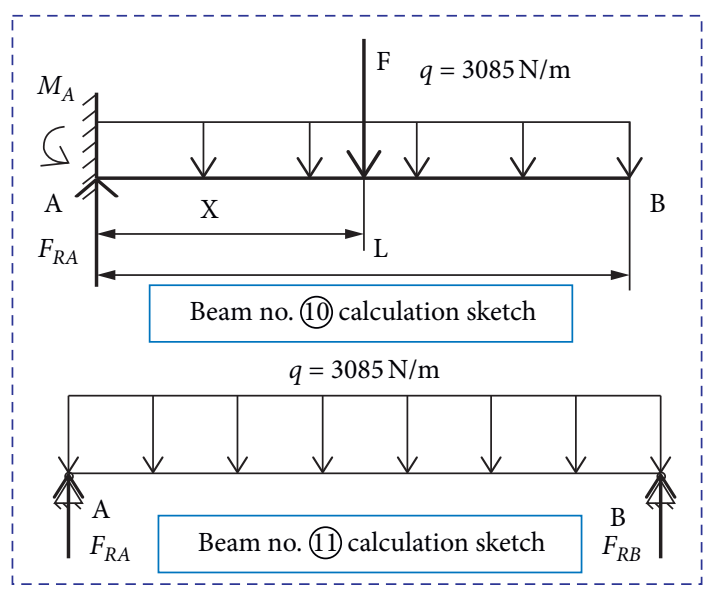

(a)

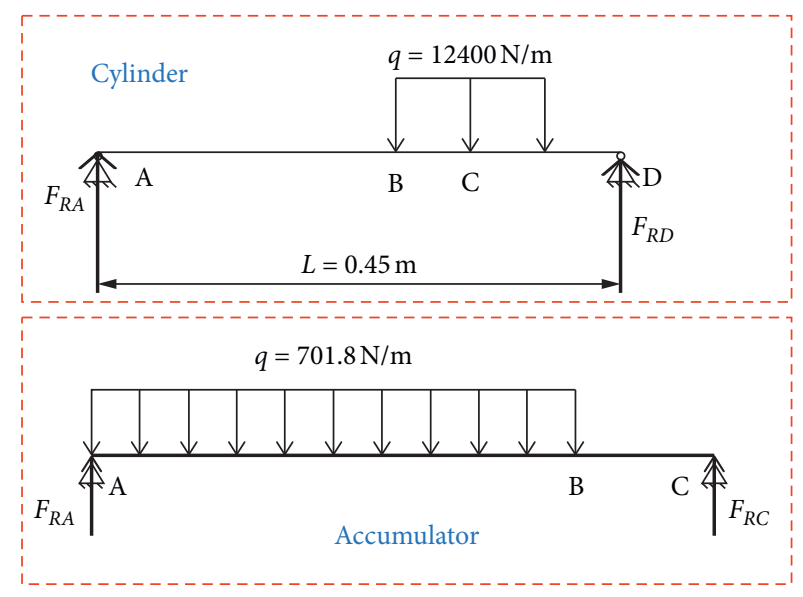

(b)

FIgURE 4: Calculation diagram of bearing beam. (a) Calculation diagram of fuel tank carrying beam. (b) Calculation diagram of cylinder and accumulator bearing beam.

entire frame was $3.807 \mathrm{~m}$ long, $2.163 \mathrm{~m}$ wide, and $1.036 \mathrm{~m}$ high. The specifications and parameters of each rectangular tube in the frame are shown in Table 3.

The material of the main frame pipe material was Q235 ordinary carbon structural steel, and its material properties are shown in Table 4.

The material of the entire frame of the combine harvester was Q235; the elastic modulus $E$ was $196 \mathrm{GPa}$; the Poisson's ratio $\mu$ was 0.25 ; the safety factor was 1.2 ; and the density of the low alloy steel was $7850 \mathrm{~kg} / \mathrm{m}^{3}$.

\subsection{Indoor Test Modal of Chassis Rack}

2.3.1. Test Mode of the Chassis Frame. In order to study the resonance of the chassis frame of the combine harvester and the excitation source of the whole machine under multisource excitation, the experimental modal test was carried out on the designed frame. The modal test system is mainly composed of an excitation system, a data acquisition system, and a modal analysis and processing system. The excitation system includes an excitation part and a vibration pickup part. The excitation part is composed of a set of PCB force hammer excitation devices, and the vibration pickup part is composed of several three-way acceleration sensors and several data connection lines. The test procedure and test equipment of the chassis frame modal test are shown in Figure 5.

According to the existing test conditions, the hammer excitation method was adopted in the modal test in this paper. The sensors used in the test were PCB piezoelectric three-way acceleration sensors with a permanent magnet base, which was easy to install and had less additional mass to the main frame. The instrument parameters required for the modal test of the chassis frame of the crawler combine harvester are shown in Table 5.

In the modal test of the chassis frame, the final results under different constraints may be completely different. The frame of the combine harvester is always in a fixed constraint
TABLE 3: Specification of the rectangular tube.

\begin{tabular}{lc}
\hline Specification & Wall thickness \\
\hline $15 * 15$ & $0.6 \sim 2.0$ \\
$25 * 25$ & $0.6 \sim 3.0$ \\
$40 * 40$ & $1.0 \sim 3.5$ \\
$18 * 18$ & $0.6 \sim 2.0$ \\
$34 * 34$ & $1.0 \sim 3.5$ \\
$50 * 50$ & $1.2 \sim 4.0$ \\
$16 * 16$ & $0.6 \sim 2.0$ \\
$30 * 30$ & $0.8 \sim 3.0$ \\
$48 * 48$ & $1.2 \sim 3.5$ \\
$20 * 20$ & $0.6 \sim 2.0$ \\
$38 * 38$ & $1.0 \sim 3.5$ \\
$60 * 60$ & $1.2 \sim 4.0$ \\
$10 * 20$ & $0.6 \sim 2.0$ \\
$20 * 40$ & $0.6 \sim 3.0$ \\
$30 * 40$ & $0.8 \sim 3.5$ \\
$40 * 60$ & $0.8 \sim 4.0$ \\
$40 * 100$ & $1.2 \sim 4.0$ \\
$50 * 90$ & $1.2 \sim 4.0$ \\
$14 * 20$ & $0.6 \sim 2.0$ \\
$20 * 50$ & $0.6 \sim 3.0$ \\
$30 * 50$ & $0.8 \sim 3.5$ \\
$40 * 70$ & $1.0 \sim 4.0$ \\
$40 * 120$ & $1.2 \sim 5.0$ \\
$50 * 100$ & $1.2 \sim 4.0$ \\
\hline
\end{tabular}

state in the actual working conditions. At the same time, the chassis frame and the vibration sources are connected to each other as a whole. The constraints added in this modal test should try to restore the actual constraint state of the chassis frame, and the support structure of the chassis frame can better reflect the actual situation. Therefore, the chassis frame can be placed on the ground for modal test. The chassis rack was placed on the ground for testing, as shown in Figure 6(a).

In this paper, the multipoint excitation and multipoint response methods are used to select two excitation points for testing, respectively, and the reliability of the data is 
TABLE 4: Material properties of the combine harvester frame.

\begin{tabular}{lccccccc}
\hline $\begin{array}{l}\text { Density } \\
\left(\rho / \mathrm{g} \cdot \mathrm{cm}^{3}\right)\end{array}$ & $\begin{array}{c}\text { Elastic } \\
\text { modulus } \\
(\mathrm{GPa})\end{array}$ & $\begin{array}{c}\text { Poisson's } \\
\text { ratio } \mu\end{array}$ & $\begin{array}{c}\text { Yield strength } \\
\sigma_{s}(\mathrm{MPa})\end{array}$ & $\begin{array}{c}\text { Expansion rate } \\
\delta(\%)\end{array}$ & $\begin{array}{c}\text { Allowable shear } \\
\text { stress }(\tau T)(\mathrm{MPa})\end{array}$ & $\begin{array}{c}\text { Allowable bending } \\
\text { stress }(\sigma-1)(\mathrm{MPa})\end{array}$ & $\begin{array}{c}\text { Extrusion } \\
\text { strength } \sigma_{b s} \\
(\mathrm{MPa})\end{array}$ \\
\hline 7.85 & 196 & 0.25 & 225 & 24 & $15 \sim 25$ & $\begin{array}{c}40 \\
120 \sim 150(\mathrm{static} \\
\text { load })\end{array}$ \\
\hline
\end{tabular}

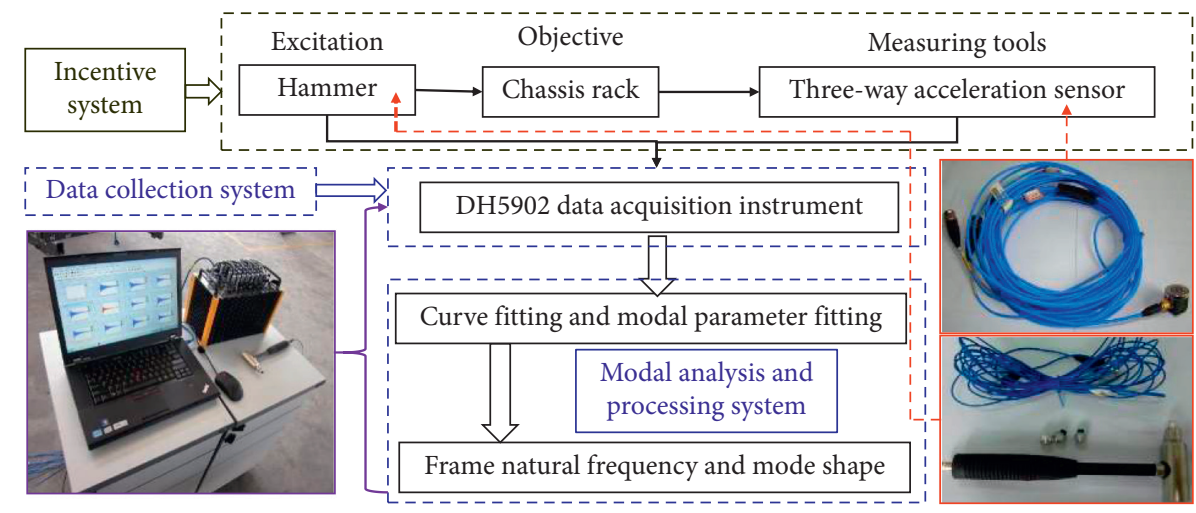

FIgURE 5: Flow chart of modal test and test equipment.

TABLE 5: Equipment and its parameters required for the modal test.

\begin{tabular}{|c|c|c|c|c|}
\hline $\begin{array}{l}\text { Serial } \\
\text { number }\end{array}$ & Device name & Model & Manufacturer & Main parameters \\
\hline 1 & Exciting hammer & $086 \mathrm{D} 05$ & PCB & Sensitivity: $10 \mathrm{mV} / 1 \mathrm{bf}$; range: $\pm 500 \mathrm{lbf} \mathrm{pk}$ \\
\hline 2 & Nylon hammer head & $086 \mathrm{D} 05$ & $086 \mathrm{D} 05$ & Sensitivity: $0.2374 \mathrm{mv} / \mathrm{N}$ \\
\hline 3 & Accelerometer & $356 \mathrm{~A} 16$ & PCB & $\begin{array}{c}\text { Quantity: 4; sensitivity: } 100 \mathrm{mV} \cdot \mathrm{g}^{-1} \text {; frequency response: } 0.3-6 \mathrm{kHz} \\
\text { range: } \pm 50 \mathrm{~g} \mathrm{pk} \text {; lateral sensitivity: }<5 \%\end{array}$ \\
\hline 4 & $\begin{array}{l}\text { Signal acquisition } \\
\text { instrument }\end{array}$ & DH5902 & DongHua test & $\begin{array}{c}\text { Quantity: } 1 \text {; number of channels: } 36 \text {; sampling bandwidth: } 16,100 \mathrm{kHz} \text {; } \\
\text { end scale value: } \pm 20 \mathrm{mv} \pm 20 \mathrm{~V}\end{array}$ \\
\hline 5 & Computer & ThinkPad & Lenovo & - \\
\hline
\end{tabular}

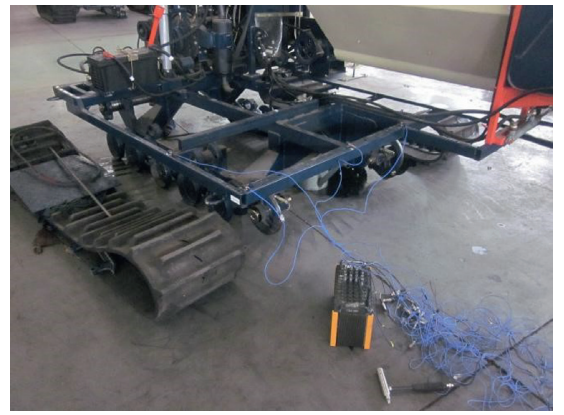

(a)

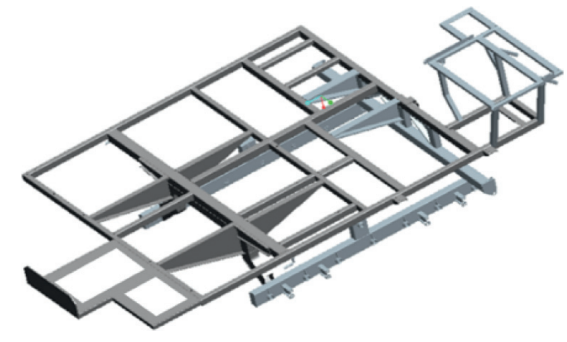

(b)

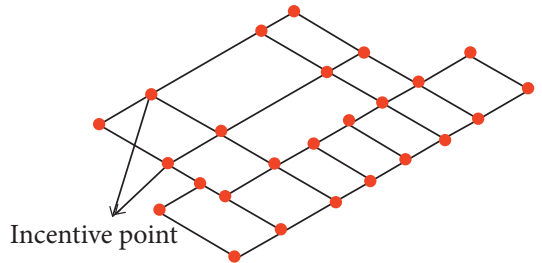

(c)

FIgure 6: Chassis frame modal test. (a) Chassis frame modal test scene. (b) 3D drawing of chassis frame. (c) Modal test model.

guaranteed through two data acquisition and parameter identification. Generally, the location of the excitation point is selected as a position with greater rigidity on the structure, which facilitates the transfer of excitation energy and facilitates manual percussion. The measurement points are mainly distributed at the key parts and connection points of the chassis frame and the shaft end of each main vibration source. The chassis frame model designed in this paper is shown in Figure 6(b), which was needed to be simplified in the modal test. During the test, 25 chassis were arranged on the chassis frame as shown in Figure 6(c). The distribution of each measuring point can reflect the structural characteristics of the chassis frame, and two excitation points were selected on the chassis frame to provide horizontal and vertical excitation forces, respectively.

During the modal test, the two excitation points (horizontal and longitudinal) were, respectively, struck with a hammer to provide excitation force to make the frame 
generate forced vibration. The vibration response signal of each measuring point under the excitation force was collected by three-directional acceleration sensors arranged on the frame. After setting the sensor parameters, the signal was sampled. The excitation point is hit with a hammer, and the frequency response function, pulse force signal, and coherence function of each measuring point were displayed on the signal acquisition instrument. The validity of the data was judged by the coherence function, frequency response function, and pulse force signal at each excitation. The measured frequency response function can be imported into the modal analysis software to obtain the inherent properties of the frame structure.

\subsubsection{Parameter Identification Process and Verification} Method of the Frequency Response Curve. The parameter identification of the frequency response curve is an important step of experimental modal analysis. After the frequency response function of each measuring point was measured by the sensor, a certain parameter identification method must be used to determine the inherent properties of the structure [19]. The operation status of the equipment can be monitored through modal parameter identification. The frequency domain law relies on frequency response functions for modal parameter identification.

This test adopted the frequency domain modal parameter identification method, which was carried out in two steps: The first step was to use the acceleration sensor of each measuring point to collect the acceleration time-domain signal transmitted from the excitation point and convert the time-domain signal into the frequency response of each measuring point function curve; the second step performed parameter identification on the obtained frequency response function curve and extracted the modal parameters of the stable structure it contained. Common modal parameter identification methods include the Polylscf method, peak extraction method, least square method, global polynomial fitting method, admittance circle method, and complex exponential fitting method. In this test, the Polylscf method was used to identify the parameters of the chassis frame. When the various modes of the chassis frame were obtained after parameter identification, it was required to verify correctness by using MAC criteria. The modal decision criterion (MAC) represents the degree of correlation between two sets of modal vectors. The closer the value of MAC is to 1 , the more completely correlated are the two sets of modal vectors, that is, the mode shapes are consistent.

\subsection{Vibration Test of the Chassis Frame of the Combine Harvester under Multiple Working Conditions.} Considering that there were multiple excitation sources on the combine harvester, even after the analysis and test of the test modal, it was impossible to fully determine the stability of the combine harvester when it is installed and working. The excitation of the vibration sources such as the shearing roller, longitudinal axial roller, engine, conveyor trough, fan, return plate, and vibrating screen on the combine harvester are all acting on the frame of the crawler combine harvester and then transmitted to the whole machine through the frame. Therefore, the actual whole machine vibration test needed to be carried out on the designed chassis frame. The chassis frame was installed after the static and modal tests on the combine harvester, and the corresponding vibration test was performed when the whole machine was working. The time-domain comparative analysis of the vibration intensity of the chassis frame of the combine harvester under different working conditions and the actual vibration response of the chassis frame under multiple working conditions were analyzed to verify its reliability.

\subsubsection{Time-Domain Response Test of the Chassis Frame} of the Combine Harvester under Multiple Working Conditions. The instrument used for the vibration test of the chassis frame was still the DH5902 vibration test and analysis system. Considering the accelerometer has a large frequency response range and high sensitivity, it is suitable for the collection of test signals of the combine harvester [31, 32]. Therefore, the types of sensors used were exactly the same used in the modal test. Different from the modal test, there were differences in the analysis modules used in the test. During the test, four main measuring points were arranged on the chassis frame of the combine harvester, which were distributed on the left front, left rear, right front, and right rear of the chassis frame. The specific installation method and measurement direction are shown in Figure 7.

The test was carried out in the test field. In actual use, the driver would selectively adjust the throttle or transmission path of the combine harvester more or less due to external factors such as different grains, different road topography, and different uses. Therefore, the whole machine needed to continue to work under the combination of several usage factors, and different combinations determine the engine speed, so the speed of each component and the transmission path was different. The vibration analysis of the single working condition of the crawler combine harvester can only partially reflect its vibration characteristics. In order to analyze the reliability of the designed chassis frame, a total of 4 working conditions were analyzed in the static idle load of the whole machine (only the engine works, small throttle), the complete machine walks (only the engine works), the static idle load of the whole machine (component work, small throttle), and the complete machine (component work). The vibration data of each working condition are analyzed and compared, and its vibration in the time domain is tested to analyze its reliability on the whole machine.

\subsubsection{Vibration Characteristics Test of the Chassis Frame} under Multisource Excitation. The main vibration sources on the combine harvester include the engine, roller, fan, return plate, vibrating screen, and transmission mechanism. The engine is the main vibration source of the combine. The excitation to the outside world comes from the periodic thrust generated by the combustion of high-temperature and 


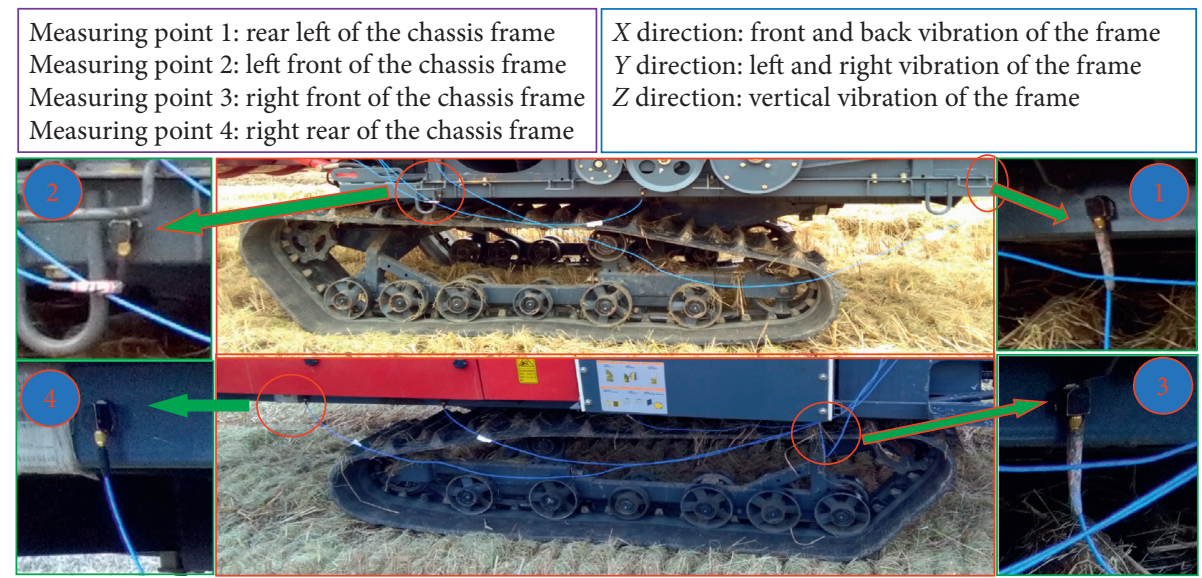

FIGURE 7: The arrangement of the chassis rack test sensors.

high-pressure gas in the engine and the unbalanced inertial force of the movement of the crank connecting rod mechanism. This test used a vertical inline 4-cylinder 4stroke diesel engine. The idling speed was $1500 \mathrm{r} / \mathrm{min}$ under the condition of small throttle, the rated speed was $2700 \mathrm{r} /$ min, and the ignition order was mainly 2 nd order. The calculation is shown as follows:

$$
f=\frac{n}{60} \times \frac{c}{2}
$$

where $f$ is the engine ignition frequency, $\mathrm{Hz} ; c$ is the number of engine cylinders; and $n$ is the engine speed, $\mathrm{r} /$ $\mathrm{rpm}$. The engine rotated at $1500 \mathrm{r} / \mathrm{min}$ under idle throttle conditions, so the calculated firing frequency was $50 \mathrm{~Hz}$, and the engine speed at $2700 \mathrm{r} / \mathrm{min}$ under high throttle conditions was $90 \mathrm{~Hz}$, that is, the operating frequency of the engine under the conditions of small throttle and large throttle. In addition to the engine, the gearbox had two speeds: input and output. The engine input power to the gearbox through HST (Hydraulic Smooth Transmission) as its input speed, which was $3000 \mathrm{r} / \mathrm{min}$, and its fundamental frequency was $50 \mathrm{~Hz}$. The output shaft of the gearbox was connected to the pulley inside the track. Taking into account that the walking speed of the combine harvester was very low, the frequency was low, generally $1 \sim 5 \mathrm{~Hz}$. Besides, the remaining excitation sources on the combine harvester also included working component excitation. The main excitation source parameters are shown in Table 6.

During the test, excitation of the chassis frame by multiple working components of the combine harvester was mainly considered. Even after the analysis of test modal, it was impossible to determine whether the chassis frame will resonate when the combine harvester was working. Therefore, it was necessary to test its vibration response when multiple components were working at the same time, mainly including three working conditions: (1) The whole machine was at no load, all components were working, and the engine was in the state of small throttle. (2) The whole machine was at no load, all components were working, and the engine was in the state of large throttle. (3) The whole machine was walking in the field, all components were working, and the engine was in the state of large throttle. The test site was the same as the chassis frame time-domain vibration test site, and all the test points and sensors and instruments used were the same.

\section{Results and Discussion}

3.1. Analysis of the Carrying Capacity of the Chassis Frame. The chassis frame adopted a three-layer structure, in which the upper frame was mainly used to carry the weight of the $\mathrm{cab}$. The purpose of using the frame structure was to increase its contact area with the cab, so that the force was uniform, and the stability of the structure was enhanced. The frame can also be used to place hydraulic oil tanks and arrange the positions of components reasonably. The middle layer of the frame was mainly used to support various components of the chassis and the grain box, engine, etc. It is formed by welding rectangular steel with different thicknesses. The lower frame was connected to the crawler walking system, and its structure is shown in Figure 2. The middle layer was the core part of the entire chassis frame, carrying the weight of the combine harvester's fuel tank, grain box, engine, cab, conveyor trough, thresher, header, and battery. Therefore, the horizontal beams in the horizontal direction were mainly used for supporting and strengthening during design. The front was the load-bearing part of the cab, engine, header, conveyor trough, and part threshing device, and the stress conditions were complex. Therefore, three vertical beams and three triangular beams were added in the vertical direction to strengthen the connection, which were welded by a beam connected to the lower frame.

3.1.1. Grain Box. Beam no. (1): according to the static balance equation,

$$
\begin{gathered}
F_{R A}+F_{R C}=q L, \\
\sum M_{A}=0 .
\end{gathered}
$$


TABLE 6: Main vibration source parameters of the combine harvester.

\begin{tabular}{lcc}
\hline Main excitation sources & Rotational speed $(\mathrm{rpm})$ & Vibration frequency $(\mathrm{Hz})$ \\
\hline Engine & 2700 & 90 \\
Gearbox & 3000 & 50.00 \\
Countershaft & 1425 & 23.75 \\
Tangential threshing & 680 & 11.33 \\
Cutter drive shaft & 425 & 7.08 \\
Longitudinal axial roller speed & 760 & 12.67 \\
Cross axle driving shaft speed & 500 & 8.33 \\
Fan speed & 1550 & 25.83 \\
Vibrating screen & 430 & 7.17 \\
Conveyor drive shaft & 500 & 8.3 \\
\hline
\end{tabular}

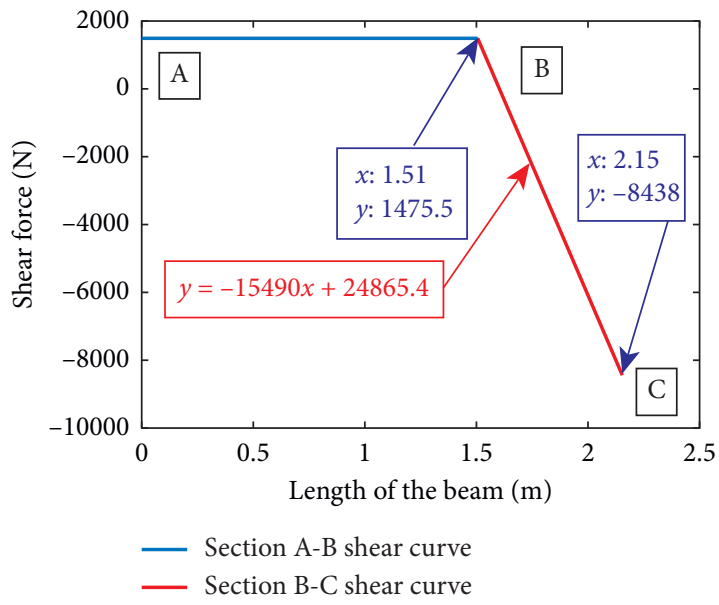

(a)

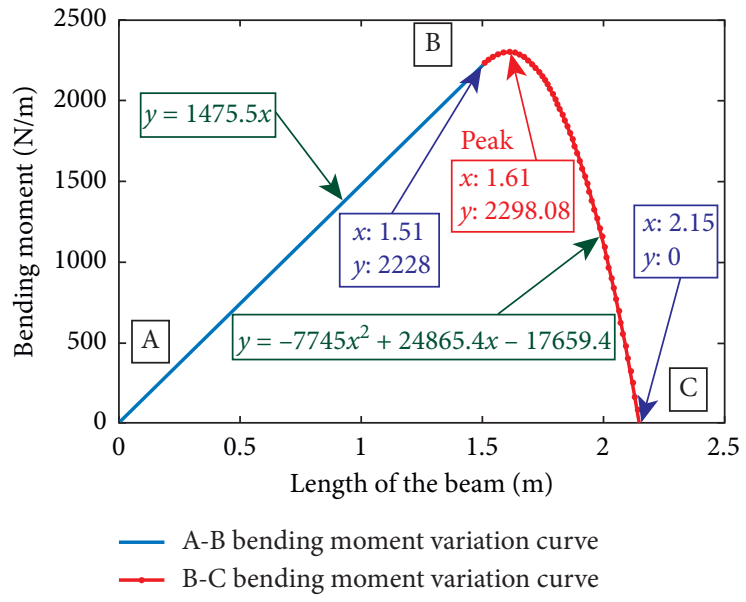

(b)

Figure 8: Beam no. (1) bearing shear and bending moment diagram. (a) Beam no. (1) shear diagram. (b) Beam no. (1) bending moment diagram.

We bring the data into the equation to get the reaction force, $F_{R A}=1475.5 \mathrm{~N}$ and $F_{R C}=8438.1 \mathrm{~N}$. The shear force diagram and bending moment diagram obtained by calculation are shown in Figures 8(a) and 8(b).

It can be seen from the curve of the bending moment experienced by the no. (1) beam that the maximum bending moment occurred at $x=1.61 \mathrm{~m}$. That is, the position where the bending failure was most likely to occur when it was loaded was within the $\mathrm{BC}$ section, and the bending moment experienced here was $2298.08 \mathrm{~N} / \mathrm{m}$.

According to the stress state of beam no. (2) and (3), relevant statics analysis was carried out. According to the static balance conditions, it was mainly divided into three parts: $\mathrm{A}-\mathrm{B}, \mathrm{B}-\mathrm{C}$, and $\mathrm{C}-\mathrm{D}$ which were analyzed separately.

Bringing the data into equations (4) and (5), $F_{R A}=400.4 \mathrm{~N}$ and $F_{R C}=1458.4 \mathrm{~N}$. From the static balance equation, the shear diagram and bending moment diagram of beam no. (2) and (3) can be obtained as shown in Figures 9(a) and 9(b).

It can be drawn from Figure 9 that the maximum bending moment of beam no. (2) and (3) appeared at $x=0.476 \mathrm{~m}$, and the maximum bending moment was $185.4 \mathrm{~N} / \mathrm{m}$. It can be seen from the abovementioned calculations that the maximum bending moment of the load-bearing beam of the grain box occurred at beam no. (1) shown in Figure 8 at a distance of $1.61 \mathrm{~m}$ from the left end boundary, and the maximum bending moment was $2298.08 \mathrm{~N} / \mathrm{m}$.

3.1.2. Cab. Beam no. (4): since the load and restraint force on the beam were symmetrical to the midpoint of the span, according to the static balance condition,

$$
F_{R A}=F_{R B}=\frac{1}{2} q L
$$

According to equation (6), $F_{R A}=F_{R B}=116.25(\mathrm{~N})$.

Beam no. (6) and (7): the stress modes of these two beams and the position of the fixed support were the same as those of beam no. (4), so the calculation diagrams of the three were consistent. Due to the different sizes of the three, their respective bending moments and shear forces were also different. The shear force diagram and bending moment diagram obtained from the shear force equation and bending moment equation are shown in Figure 10. Figure 10(a) is the shearing force diagram of the three beams, and 10(b) is the bending moment diagram of the three beams. It can be seen 


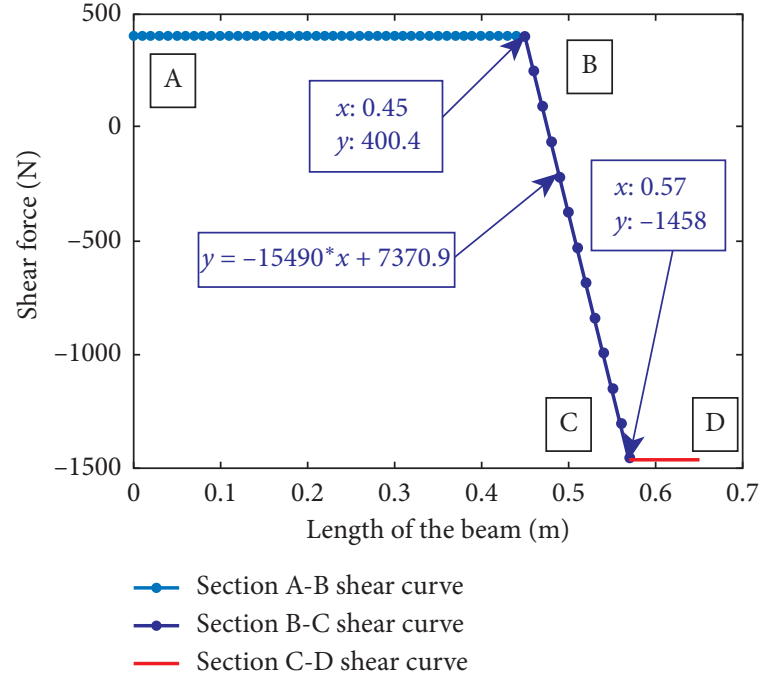

(a)

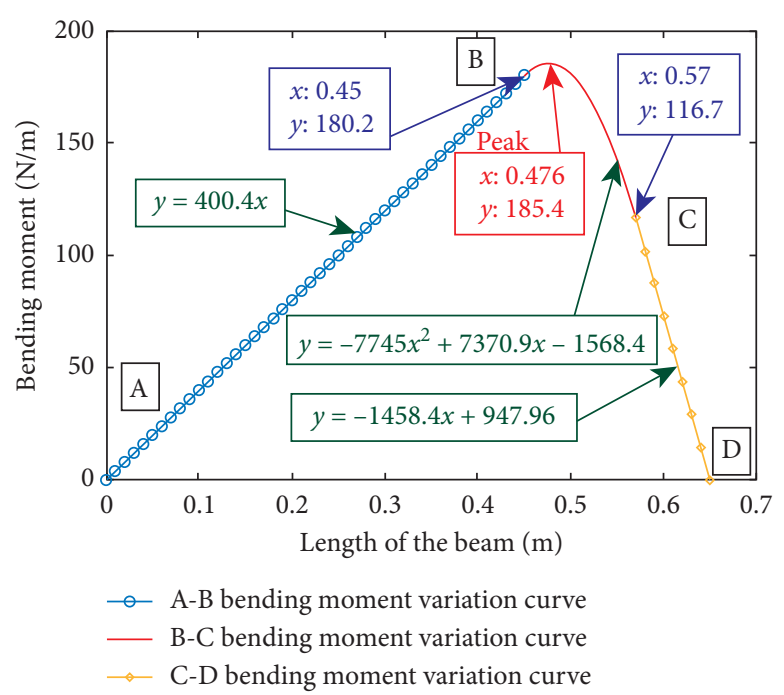

(b)

Figure 9: Beams no.(2) and (3) bearing shear and bending moment diagram. (a) Beam no. (2) and (3) shear diagram. (b) Beam no. (2) and (3) bending moment diagram.

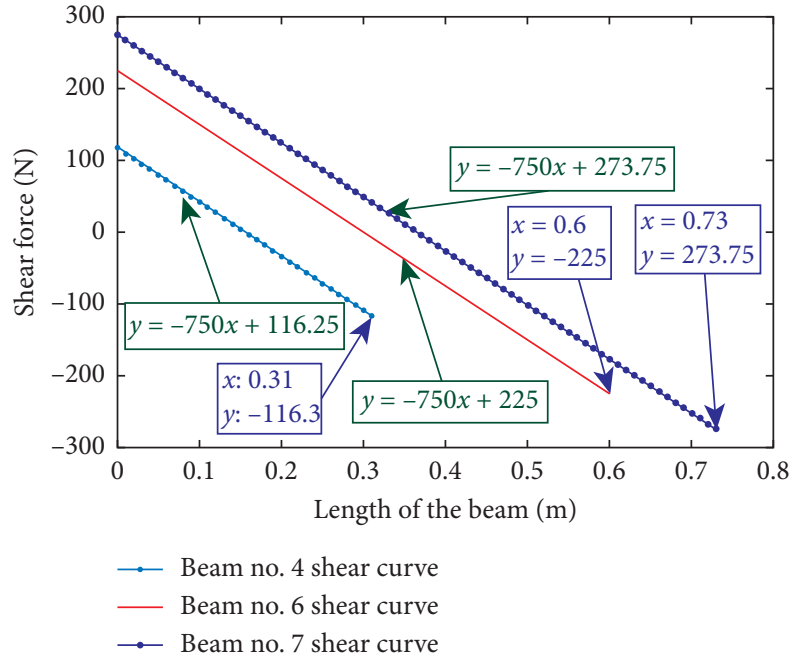

(a)

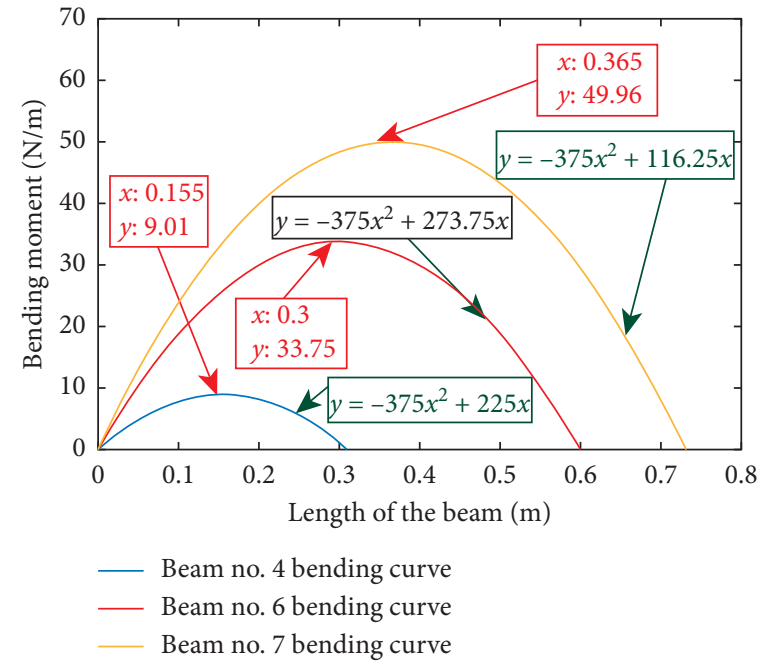

(b)

Figure 10: Beam no. (4),(6), and (7) bearing shear and bending moment diagram. (a) Beam no. (4), (6), and (7) shear diagram. (b) Beam no. (4), (6), and (7) bending moment diagram.

from Figure 10 that the maximum bending moments of beam no. (4), (6), and (7) were located at the midpoint of the beam, and the maximum bending moments were $9.01 \mathrm{~N} / \mathrm{m}$, $33.75 \mathrm{~N} / \mathrm{m}$, and $49.96 \mathrm{~N} / \mathrm{m}$, respectively.

Beam no. (5): the beam was a statically indeterminate continuous beam. Among them, the shear force at the end of section A was $F_{s 1}=q L_{1}=206.25(\mathrm{~N})$; the shear force at the left section of point B was $F_{s 2}=-206.25(\mathrm{~N})$; the shear force at the right section of point $\mathrm{B}$ was $F_{s 3}=q L_{2}=243.75(\mathrm{~N})$; the shear force at section $\mathrm{C}$ was $F_{s 4}=-243.75(\mathrm{~N})$. The shear force diagram and bending moment diagram were obtained as shown in Figures 11(a) and 11(b).

Compared with the statically indeterminate structure, the maximum value of the bending moment can be greatly reduced. It can be seen from Figure 11(b) that the maximum bending moment was $10.52 \mathrm{~N} / \mathrm{m}$. Based on the abovementioned calculations and graphics, it can be seen that, among all the load-bearing beams in the cab, the maximum bending moment occurred at the midpoint of beam no. (7) shown in Figure 10(b), and the maximum bending moment was $49.96 \mathrm{~N} / \mathrm{m}$.

3.1.3. Engine. According to the static balance condition, $F_{R A}+F_{R F}=q L_{1}+q L_{2} ; \sum M=0$. Substitute data can be calculated as $F_{R A}=346.4 \mathrm{~N}$ and $F_{R F}=1026.4 \mathrm{~N}$. According to the load conditions and calculation results of each section, the shearing force diagram and bending moment diagram of 


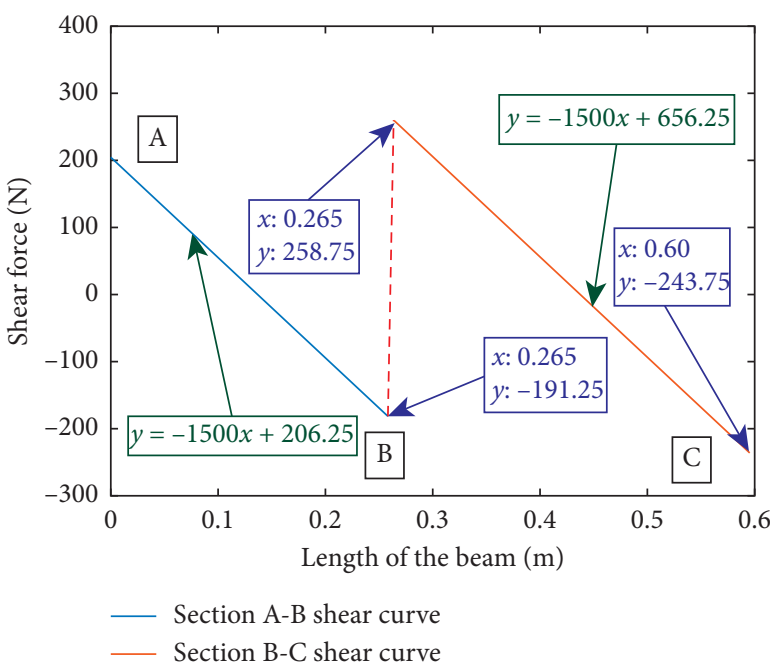

(a)

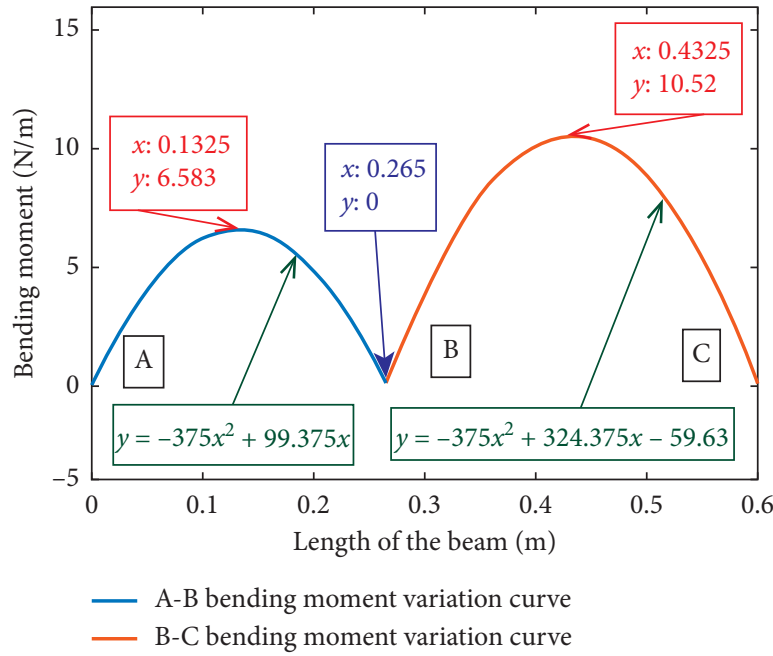

(b)

Figure 11: Beam no. (5) beam bearing shear and bending moment diagram. (a) Beam no. (5) beam shear diagram. (b) Beam no. (5) bending moment diagram.

the engine bearing beam were drawn. The results are shown in Figure 12. Figures 12(a) and 12(b) are the shear force diagram and bending moment diagram of beam (8), respectively.

It can be seen from Figure 12 that the maximum bending moment of the engine load beam was at $x=1.41 \mathrm{~m}$, where the maximum bending moment was $478.128 \mathrm{~N} / \mathrm{m}$.

3.1.4. Fuel Tank. There was a fixed load on beam no. (10), and the size was $F=771.25 \mathrm{~N}$, acting at $x=0.41 \mathrm{~m}$. From the equilibrium conditions, $M(A)=1072.04 \mathrm{~N} / \mathrm{m}$ and $F(A)=2930.75 \mathrm{~N} . M(A)$ was the bending moment at point $A$, and $F(A)$ was the large shear force at point $A$. The shear force and bending moment changes of beam no. (9) and (10) are put together for comparative analysis to find the change of shear bending moment. The results are shown in Figure 13, where (a) and (b) are the shear force diagram and bending moment diagram they were subjected to.

It can be seen from Figure 13(b) that the two cantilever beams had the largest bending moment at the left end, that is, the welding point. The bending moments were $755.825 \mathrm{~N} /$ $\mathrm{m}$ and $1024.04 \mathrm{~N} / \mathrm{m}$, respectively.

According to the static balance condition, $F_{A}=F_{B}=(1 / 2) q L=771.25 \mathrm{~N}$. From this, the shear force and bending moment of beam no. (11) and (12) can be obtained as shown in Figure 14, where (a) and (b) are the shear force diagram and bending moment diagram for them, respectively.

Based on the analysis and calculation of all the abovementioned fuel tank parts, it can be seen that the (11) beam (cantilever beam) shown in Figure 14(b) was the loadbearing beam with the largest bending moment, and the maximum bending moment was $1072.04 \mathrm{~N} / \mathrm{m}$. In particular, the position of the beam with the largest bending moment was at the left end welding place, where the section was a dangerous section.
3.1.5. Cylinder. From the static balance condition, $F_{A}+F_{D}=q L, \sum M_{A}=0$. The support force $F_{A}=216.9 \mathrm{~N}$ and $F_{D}=378.3 \mathrm{~N}$ can be obtained from this. On this basis, it can be obtained that the shear force and bending moment are shown in Figure 15, where (a) and (b) are the shear force diagram and bending moment diagram, respectively.

It can be seen from Figure 15 that the maximum bending moment of the cylinder load beam occurred at a section of $0.28 \mathrm{~m}$ from the lower end face, and the maximum bending moment was $58.72 \mathrm{~N} / \mathrm{m}$.

3.1.6. Accumulator. According to the static balance conditions, $F_{A}=150.1 \mathrm{~N}$ and $F_{C}=95.53 \mathrm{~N}$. On this basis, the shear force and bending moment can be obtained as shown in Figure 16, where (a) and (b) are the shear force diagram and bending moment diagram they were subjected to.

It can be known from the bending moment variation curve in Figure 16(b) that the maximum bending moment occurs at a distance of $0.21 \mathrm{~m}$ from the lower end section, and the maximum bending moment was $16.05 \mathrm{~N} / \mathrm{m}$.

3.1.7. Threshing Drum. The calculation method of each bearing beam of the threshing drum was the same as that of the same type of beam before. Therefore, the bending moment and the shear force of all the load-bearing beams of the threshing drum are shown in Figure 17, where (a) and (b) are the shear force diagram and bending moment diagram of beam no. (14), (16), and (17), respectively; (c) and (d) are the shear force diagram and bending moment diagram of beam no. (15); and (e) and (f) are the shear force diagram and bending moment diagram of beam no. (18), respectively.

As can be seen from the abovementioned images, among all the bearing beams of the threshing drum, beam no. (16) 


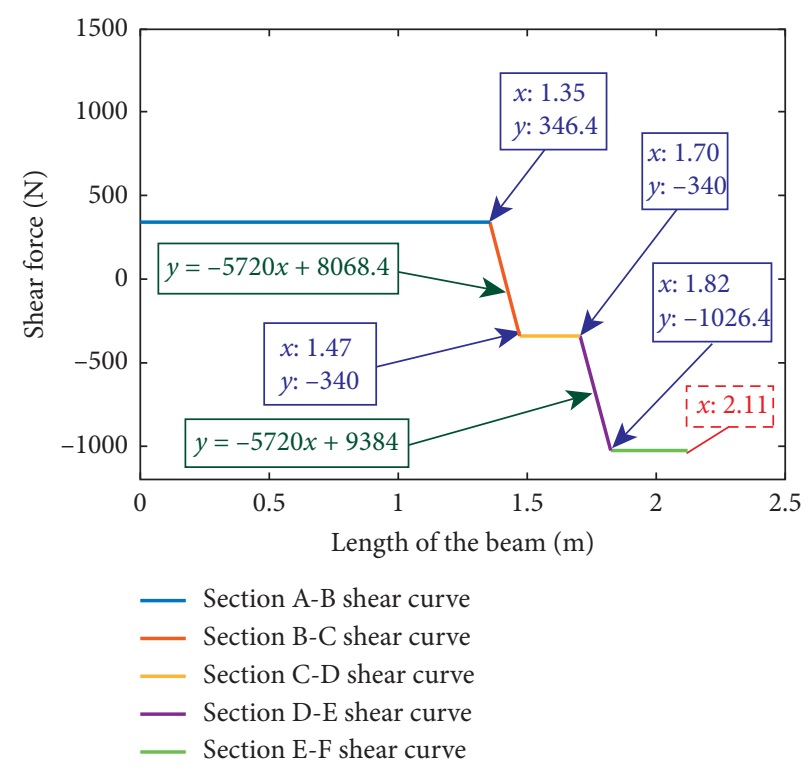

(a)

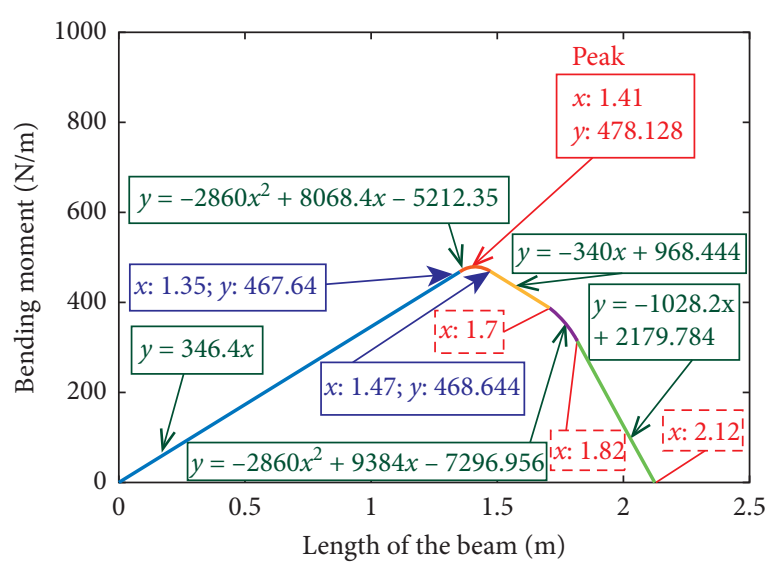

- A-B bending moment variation curve

- B-C bending moment variation curve

- C-D bending moment variation curve

- D-E bending moment variation curve

_ E-F bending moment variation curve

(b)

FIGURE 12: Engine position bearing beam shear and bending moment diagram. (a) Beam no. (8) shear diagram. (b) Beam no. (8) bending moment diagram.

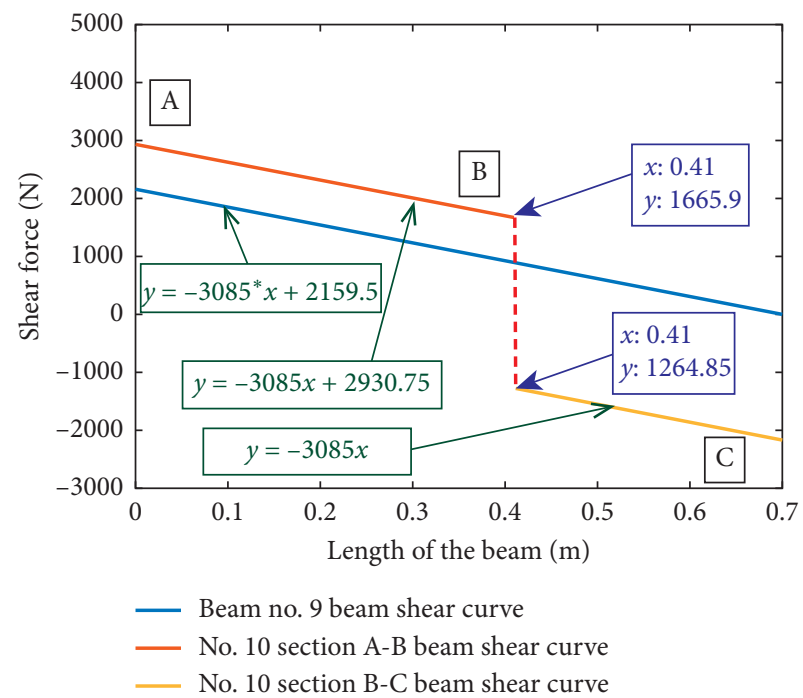

(a)

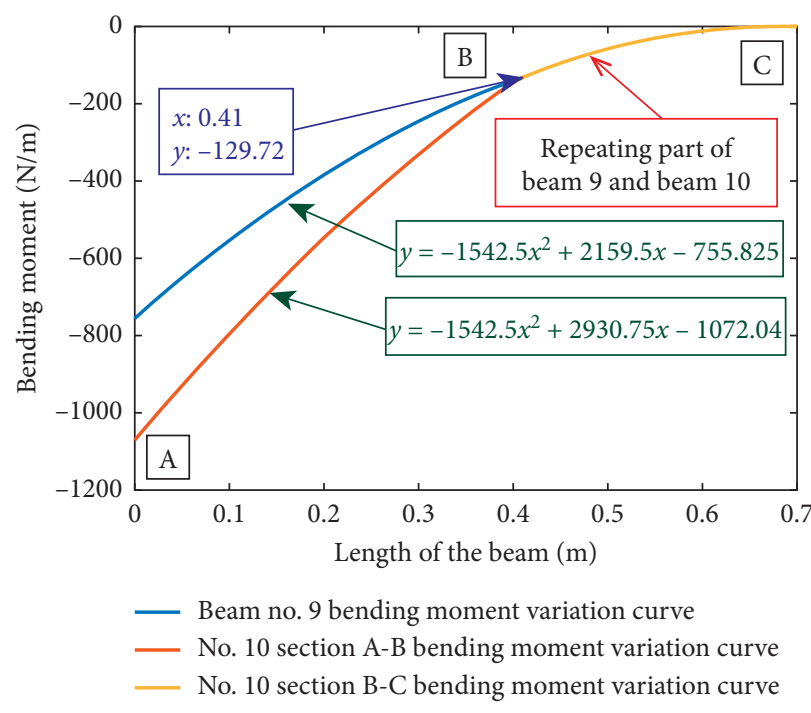

(b)

Figure 13: Beams no. (9) and (10) bearing shear and bending moment diagram. (a) Beam no. (9) and (10) shear diagram. (b) Beam no. (9) and (10) bending moment diagram.

was subjected to the maximum bending moment which appeared at the midpoint of the beam with $486.875 \mathrm{~N} / \mathrm{m}$.

After the mechanical analysis and calculation of the main load-bearing beams (mainly shear force and bending moment), it can be known that, at full load, the maximum bending moment of all load-bearing beams appeared on one of the load-bearing beams of the grain box, and the maximum bending moment was recorded as $M_{\max }$. From all the abovementioned data, $M_{\max }=2298.08 \mathrm{~N} / \mathrm{m}$, and it was located at the cross section of beam no. (1) $1.61 \mathrm{~m}$ away from the left boundary.

When the beam was bent by force, the bending moment would change with the position of the section. Also, in general, the maximum normal stress $\sigma_{\max }$ occurred at the section with the largest bending moment (dangerous section). The cross section of the beam was a hollow rectangular section. The calculation of the bending section coefficient of the hollow rectangle is shown in equation (7), and the 


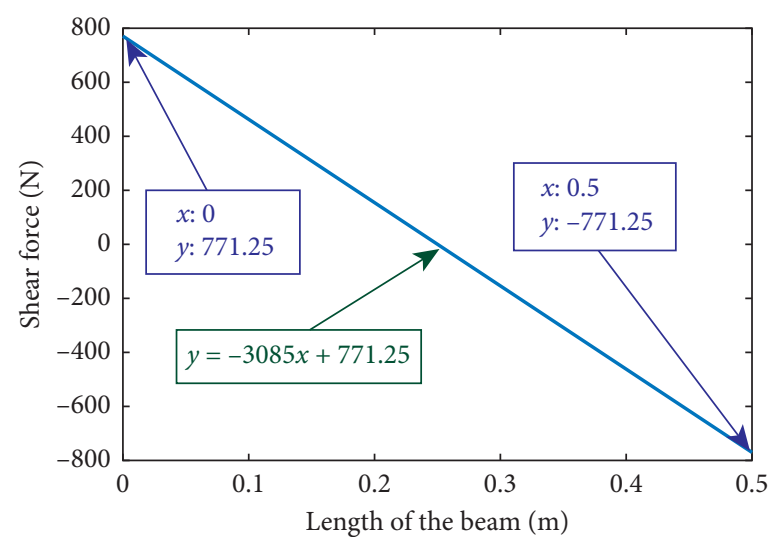

- No. 11 and no. 12 beam shear curve

(a)

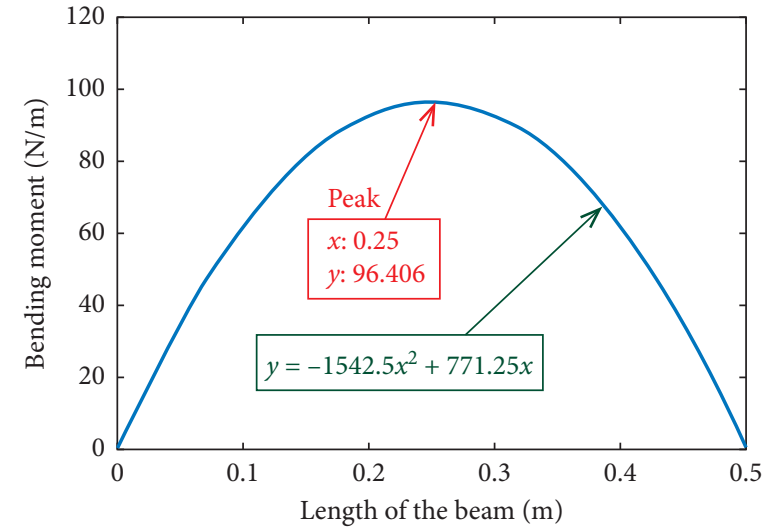

Beam no. 11 and no. 12 beam bending moment curve

(b)

Figure 14: Beams no. (11) and (12) bearing shear and bending moment diagram. (a) Beam no. (11) and (12) shear diagram. (b) Beam no. (11) and (12) bending moment diagram.

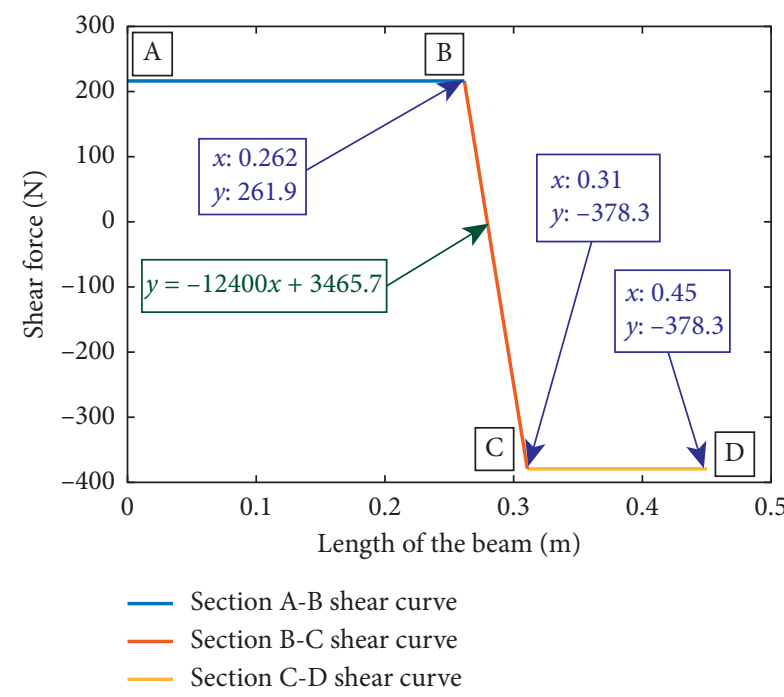

(a)

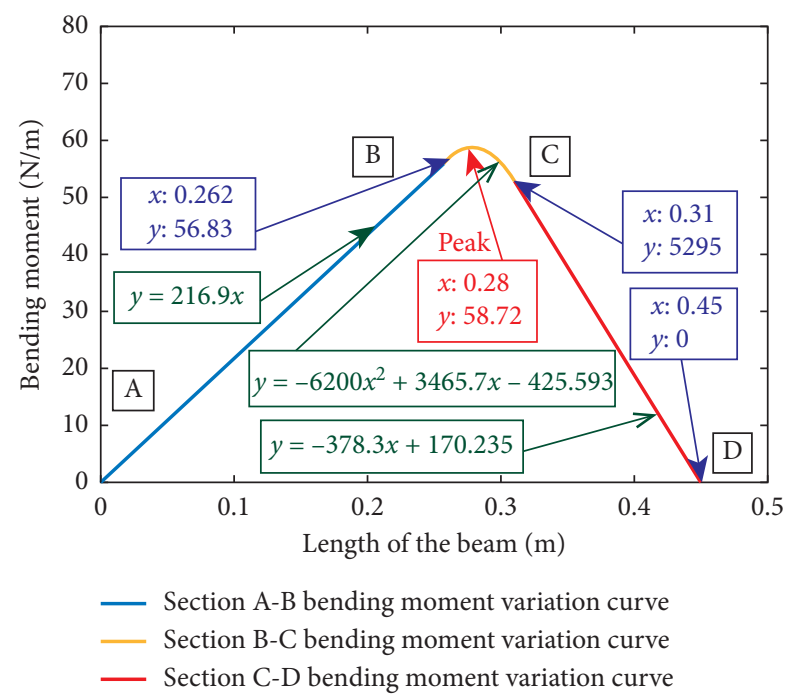

(b)

Figure 15: Diagram of shear force and bending moment of cylinder bearing beam. (a) Shear diagram of cylinder load beam. (b) Bending moment diagram of cylinder load beam.

equation for calculating the stress during bending with transverse force is shown in equation (8) [30].

$$
\begin{gathered}
W_{Z}=\frac{B H^{3}-b h^{3}}{6 H}, \\
\sigma_{\max }=\frac{M_{\max }}{W_{Z}} \leq[\sigma],
\end{gathered}
$$

where $H$ is the length of the quadrilateral outside the rectangular tube; $h$ is the length of the quadrilateral in the rectangular tube; $B$ is the width of the quadrilateral outside the rectangular tube; and $b$ is the width of the quadrilateral in the rectangular tube; it can be calculated by bringing the data into equations (7) and (8), $W_{z}=$ $23180.3\left(\mathrm{~mm}^{3}\right)=2.32 \times 10^{-6}\left(\mathrm{~m}^{3}\right)$ and $\sigma_{\max }=99.1 \mathrm{MPa}$. The material of the beam is Q235, and the yield strength of $\mathrm{Q} 235$ is $235 \mathrm{MPa}$, that is, $[\sigma]=235 \mathrm{MPa}$. Therefore, $\sigma_{\max }=99.1 \mathrm{MPa}<[\sigma]$, which met the requirements of Q235.

3.2. Test Modal Results and Analysis. The first 6-order modal frequencies, damping ratios, and mode shapes of the test modes of the chassis frame can be obtained. The calculated modal frequency was checked by the Modal Judgment Criterion (MAC), and the correlation between the modal frequencies of each order was close to zero indicating that 


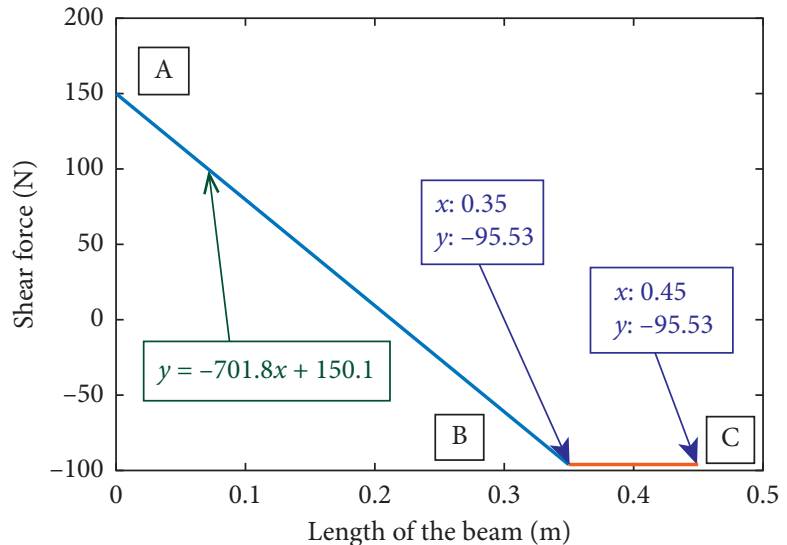

- Section A-B shear curve Section B-C shear curve

(a)

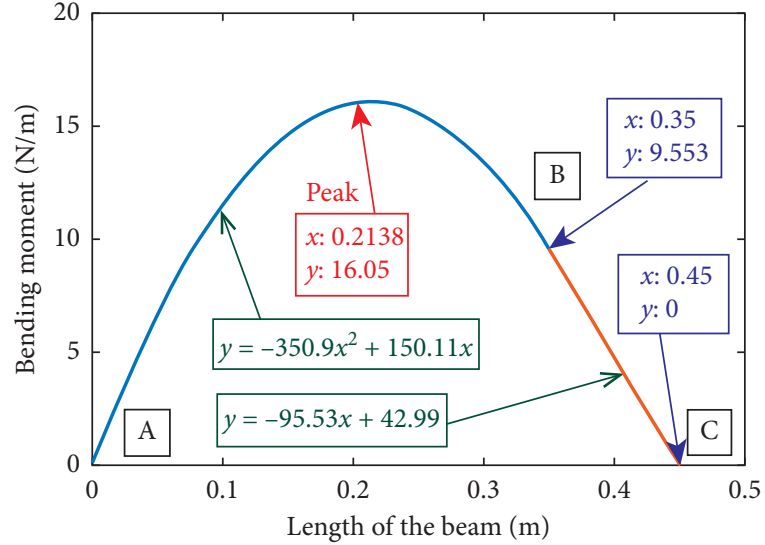

Section A-B bending moment variation curve Section $\mathrm{B}-\mathrm{C}$ bending moment variation curve

(b)

FIGURE 16: Shear force and bending moment of the accumulator bearing beam. (a) Shear diagram of accumulator bearing beam. (b) Bending moment diagram of accumulator bearing beam.

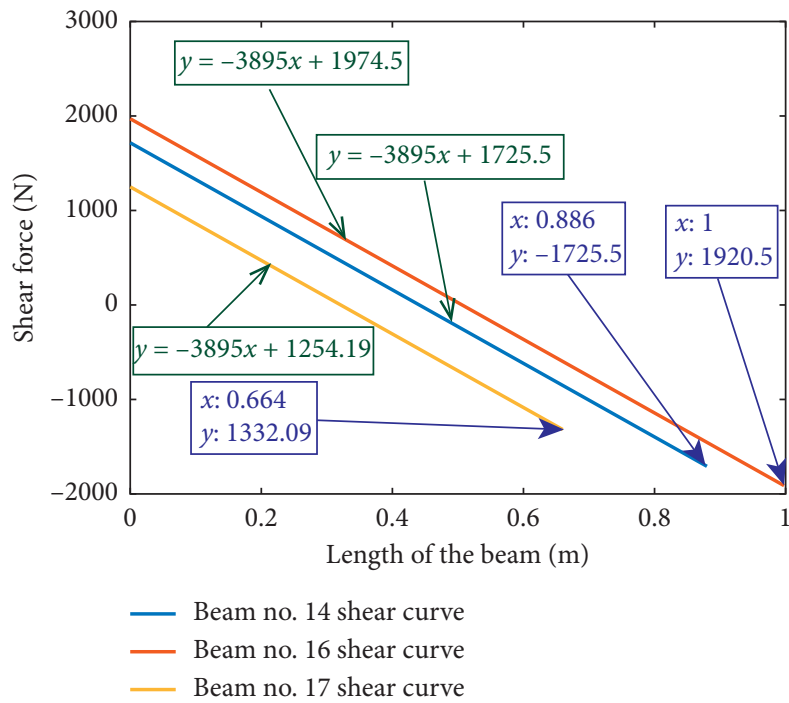

(a)

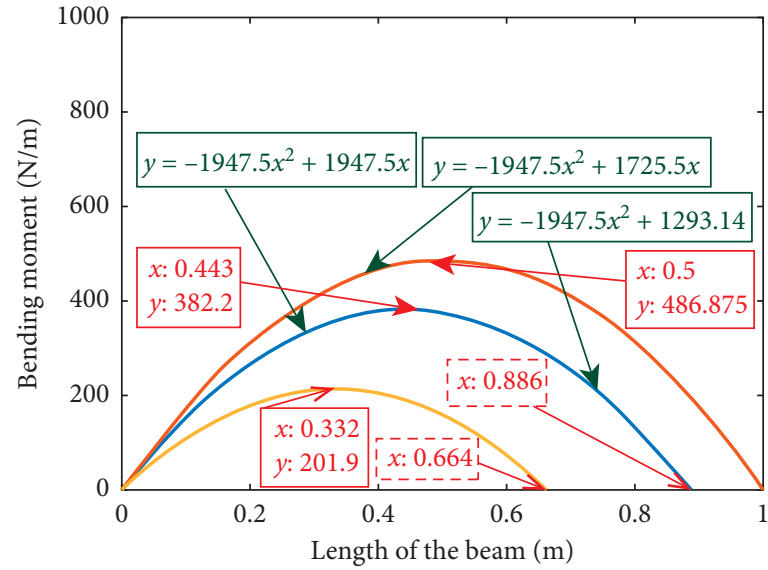

- Beam no. 14 bending moment change curve

_- Beam no. 16 bending moment change curve

_ Beam no. 17 bending moment change curve

FIgURE 17: Continued. 


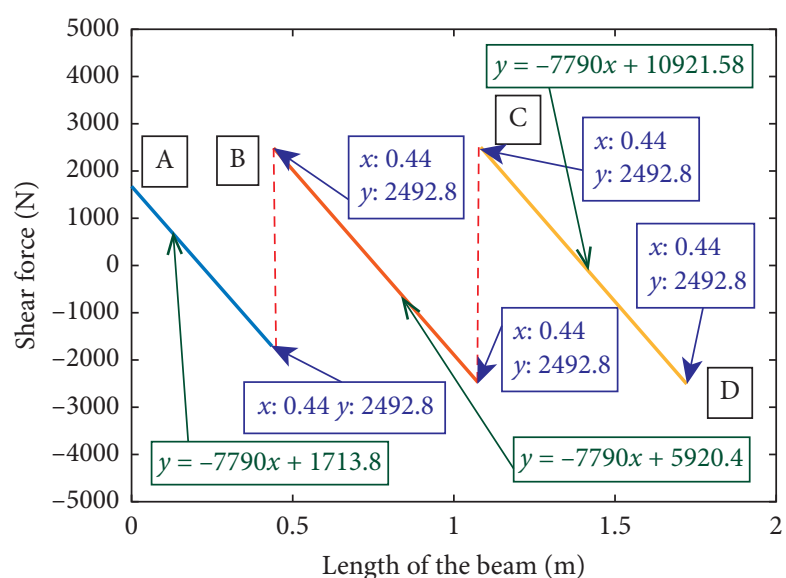

— Section A-B shear curve

(c)

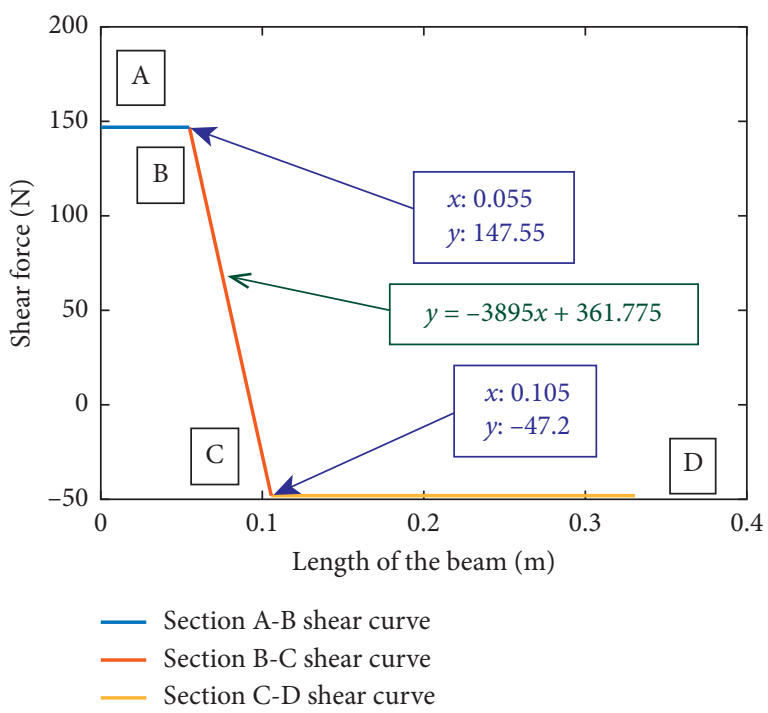

(e)

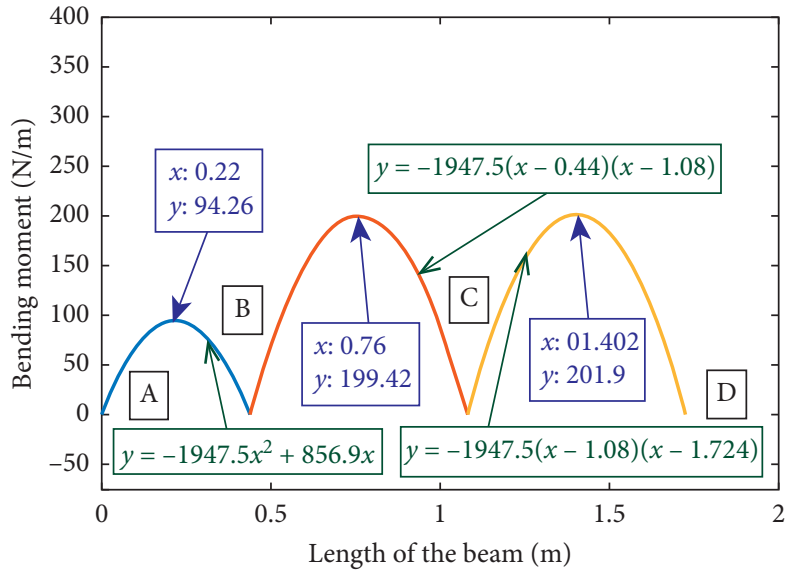

- Section A-B bending moment variation curve

- Section B-C bending moment variation curve

_ Section C-D bending moment variation curve

(d)

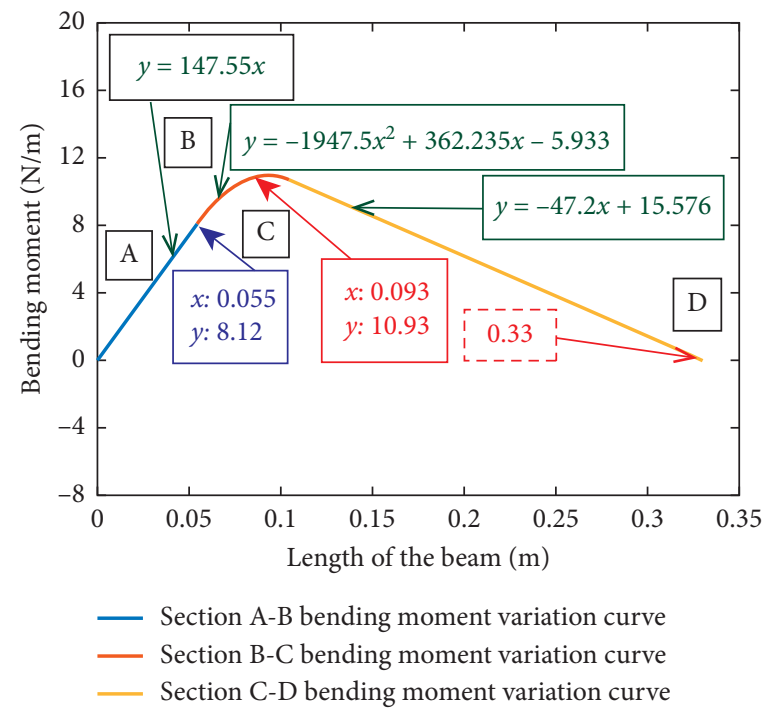

(f)

FIGURE 17: Shear force and bending moment of each bearing beam of the threshing drum. (a) Beams no. (14), (16), and (17) shear diagram. (b) Beam no. (14), (16), and (17) bending moment diagram. (c) Beam no. (15) shear diagram. (d) Beam no. (15) bending moment diagram. (e) Beam no. (18) shear diagram. (f) Beam no. (18) bending moment diagram.

the calculated modal parameters were valid; the verification results and the modal shapes of each order of the chassis frame are shown in Figure 18.

The modal analysis of the crawler-type combined harvesting chassis frame test is shown in Table 7.

It can be seen from the data in Table 7 that the first six natural frequencies of the chassis frame were between $22-53 \mathrm{~Hz}$, and the vibration modes were mainly bending, torsion, and local modes. The first-order natural frequency of $23.77 \mathrm{~Hz}$ was close to the double frequency of the longitudinal axial drum rotation frequency of $25.34 \mathrm{~Hz}$ and the fundamental frequency of the fan speed was $25.83 \mathrm{~Hz}$, which may produce complex vibration coupling and easily excite the bending mode of the tank support beam. The fifth-order natural frequency of the chassis frame of $45.38 \mathrm{~Hz}$ was close to the basic frequency of the engine at $45 \mathrm{~Hz}$ at idle speed and large throttle, which was easy to excite the bending mode of the fuel tank support beam.

Considering that the frequency of each vibration source would be fluctuated during the field harvesting process of the combine harvester, the fundamental frequency of each vibration source and its multiplier frequency cannot be calculated by only a certain instantaneous speed. Therefore, it was more accurate and practical to analyze and study the excitation frequency of each vibration source in a certain frequency range. It can be seen from Table 7 that the excitation frequency of each vibration source on the combine was concentrated in two interval sections of $20-25 \mathrm{~Hz}$ and $45-50 \mathrm{~Hz}$. Therefore, in these two interval sections, the fundamental frequency or 
and its multiplier frequency of each vibration source may be close to each other or even produce frequency coupling; furthermore, the vibration of the whole machine could also reach a peak in these two frequency sections. In addition, the first 6-order natural frequencies of the chassis frame were within the operating frequency range of multiple vibration sources on the combine. There was more overlap between $20-25 \mathrm{~Hz}$ and $40-45 \mathrm{~Hz}$, which may cause complex vibration coupling and resonance. As a result, the whole machine vibrated violently during operation, which can easily cause fatigue damage to key components and greatly reduce the service life of the combine harvester.

\subsection{Vibration of the Chassis Frame of the Combine Harvester under Multiple Operating Conditions}

3.3.1. Time-Domain Vibration Characteristics of the Chassis Frame of the Combine Harvester under Multiple Operating Conditions. After the tests, the data collected from each channel of the sensors was processed by the $\mathrm{DH}$ vibration test analysis software. The working conditions during the analysis mainly include the following four conditions: working condition 1: whole machine static no load (only the engine worked, small throttle); working condition 2: whole machine walking (only the engine working); working condition 3: whole machine static no load (components working, small throttle); and working condition 4: the whole machine walking (components working). The data in all directions were calculated and counted to obtain the timedomain average of the main vibration acceleration of the chassis frame in three directions. The specific data results are shown in Table 8 and Figure 19.

In order to explore the vibration amount of the chassis frame under multiple working conditions, considering the existence of three directions of vibration at the same measuring point, it was necessary to calculate the total root mean square acceleration of each measuring point under different working conditions in three directions. The root mean square acceleration of the total vibration of the measuring point in the rectangular coordinate system can be calculated by

$$
a_{v}=\sqrt{\frac{a_{x}^{2}+a_{y}^{2}+a_{z}^{2}}{3}}
$$

From the vibration acceleration data in Table 8, the root mean square acceleration of the total amount of vibration of each measuring point under various working conditions can be obtained. The specific data results are shown in Table 9.

From the vibration acceleration results of the sensors in Tables 8 and 9, it can be seen that the vibration acceleration of the chassis frame was the smallest under working condition 1 . Under working condition 4 , the vibration acceleration of the chassis frame was the largest; that meant that when the whole machine and each component was working, the impact of each working component on the chassis frame was the largest. In this condition, the vibration of the chassis frame at the right rear was severe, which was the position of the threshing and cleaning working device. The main excitation direction at this position was in the $Z$-direction which was the carrying direction of the chassis frame. Although the statics had been checked before the design, when the threshing drum was actually working, there would be a large unbalanced excitation force due to the threshing work. Under the action of persistent unbalanced staggered excitation force, it would cause the chassis frame to produce periodic forced vibration here. Therefore, the support frame at this position should be further strengthened to improve the long-term reliability of the chassis frame, thereby improving the reliability of the entire machine.

\subsubsection{Vibration Characteristics of Chassis Frame under} Multisource Excitation. Taking the $X$-direction vibration response of the front left measurement point of the chassis frame as an example, the result of the vibration acceleration signal after being transformed by someone is shown in Figure 20. The specific frequency amplitude of the combine harvester under three working conditions of the static load of the complete machine (components working, small throttle), the static load of the complete machine (components working, large throttle), and the whole machine walking (components working) is shown in Tables 10 12. Comparing the frequency of the main vibration source parameters of the combine harvester in Table 6 with the data in Table 10, it can be seen that the main frequency of vibration in each direction of the measurement points was basically the second-order frequency doubling of the engine under the condition of small throttle at idle speed and each order octave. The vibration amplitude of the chassis frame near the bracket responsible for carrying the engine was the largest in the lateral direction, followed by the vertical direction. It could be that the engine was installed on the chassis frame at an angle, which caused the vertical excitation force generated by the combustion torque of the engine to decompose in the lateral and vertical directions.

By analyzing the four response points of the chassis frame, it can be seen that the measurement point at the left rear of the chassis frame had large amplitude at $15 \mathrm{~Hz}$, which may be the double frequency of the fundamental frequency of the driving shaft of the bridge or the drive shaft of the vibrating screen. Since the vibrating screen structure was a crank-slider mechanism, when the vibrating screen drive shaft worked, the reciprocating motion of the slider would have a periodic impact on the frame, resulting in large local amplitude of the chassis frame. When the whole machine was moving in the field with all working components working, the vibration amplitude of the chassis frame was the largest. As the engine speed increased, the excitation capacity of each working component connected to the engine on the whole machine increased, resulting in an increase in the frequency component and amplitude of the measuring point on the chassis frame. Among them, each working 


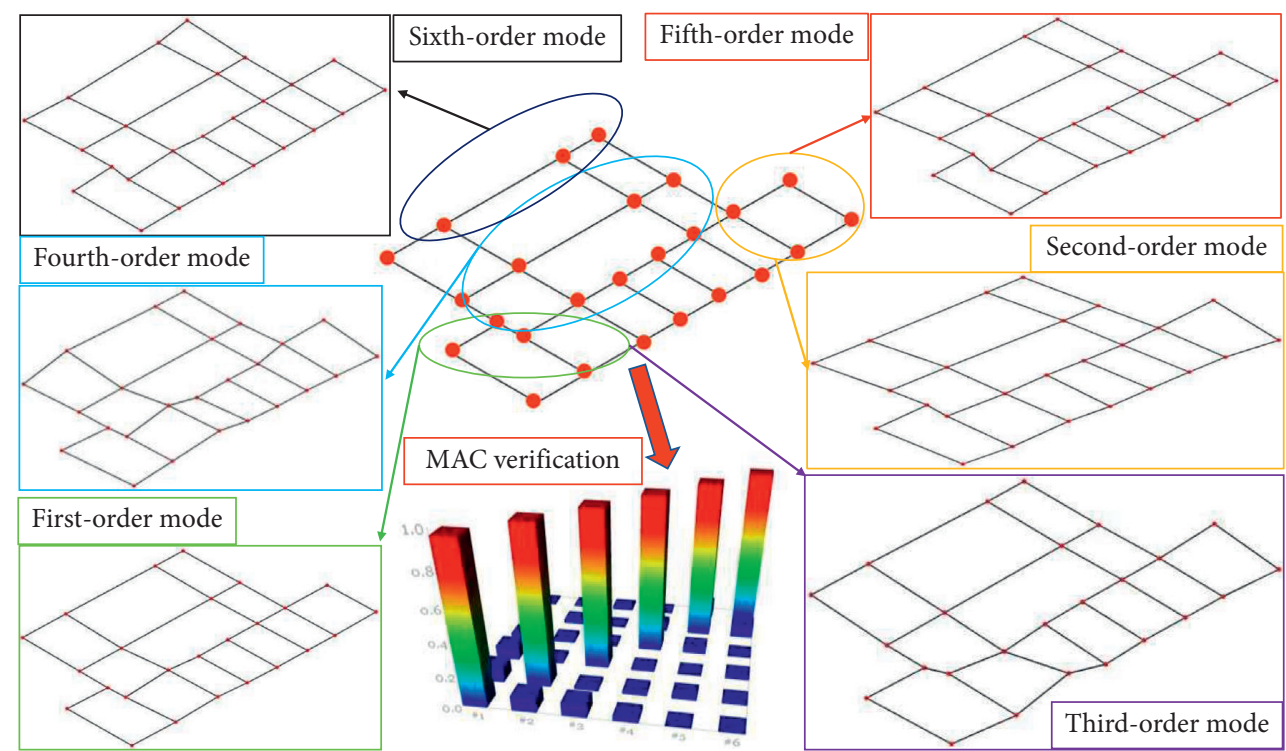

FIGURE 18: Natural frequency and modal shapes of the chassis frame.

TABLE 7: Comparison of modal test and finite element calculation results.

\begin{tabular}{|c|c|c|c|c|c|}
\hline \multirow{2}{*}{$\begin{array}{l}\text { Research } \\
\text { object }\end{array}$} & \multirow[b]{2}{*}{ Order } & & \multicolumn{2}{|r|}{ Modal test results } & \multirow[b]{2}{*}{ Deviation (\%) } \\
\hline & & $\begin{array}{l}\text { Test frequency } \\
(\mathrm{Hz})\end{array}$ & $\begin{array}{c}\text { Damping ratio } \\
(\%)\end{array}$ & Mode shape & \\
\hline \multirow{6}{*}{ Chassis frame } & 1 & 23.77 & 0.22 & Fuel tank support beam bending & 1.3 \\
\hline & 2 & 28.91 & 0.47 & Cab beam bending and torsion combination & 2.8 \\
\hline & 3 & 35.41 & 0.72 & Fuel tank support beam bending & 0.9 \\
\hline & 4 & 42.44 & 0.16 & $\begin{array}{c}\text { Overall bending and twisting combination of chassis } \\
\text { frame }\end{array}$ & 8.5 \\
\hline & 5 & 45.38 & 0.53 & Fuel tank support beam bending & 5.4 \\
\hline & 6 & 52.62 & 0.58 & Left beam bending & 3.6 \\
\hline
\end{tabular}

TABLE 8: Time-domain comparison of vibration intensity under various working conditions.

\begin{tabular}{|c|c|c|c|c|c|c|c|c|c|c|c|c|}
\hline \multirow{3}{*}{ Measuring point } & \multicolumn{12}{|c|}{ Root mean square value of vibration acceleration $\left(\mathrm{m} / \mathrm{s}^{2}\right)$} \\
\hline & \multicolumn{3}{|c|}{ Working condition 1} & \multicolumn{3}{|c|}{ Working condition 2} & \multicolumn{3}{|c|}{ Working condition 3} & \multicolumn{3}{|c|}{ Working condition 4} \\
\hline & $X$ & Y & $Z$ & $X$ & Y & $Z$ & $X$ & Y & $Z$ & $X$ & Y & $Z$ \\
\hline 1 & 0.57 & 0.74 & 0.55 & 2.83 & 2.15 & 5.36 & 2.13 & 3.89 & 5.89 & 4.37 & 4.96 & 9.36 \\
\hline 2 & 0.62 & 0.82 & 0.87 & 2.47 & 2.71 & 4.23. & 3.45 & 2.83 & 4.03 & 4.12 & 5.58 & 5.68 \\
\hline 3 & 0.84 & 1.02 & 1.05 & 2.06 & 2.01 & 2.35 & 3.50 & 3.64 & 9.01 & 4.59 & 5.17 & 10.08 \\
\hline 4 & 0.68 & 0.79 & 0.98 & 2.87 & 3.23 & 3.89 & 2.67 & 9.17 & 6.44 & 3.32 & 9.97 & 12.25 \\
\hline
\end{tabular}

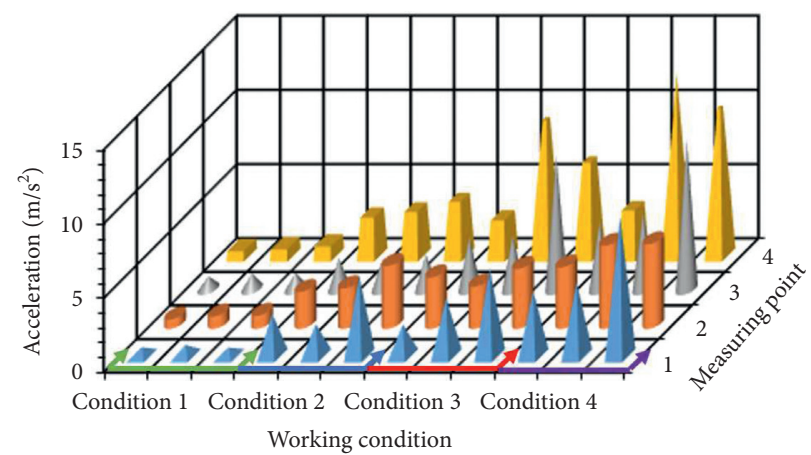

FIGURE 19: Root mean square value of vibration acceleration under various working conditions. 
TABLE 9: Root mean square acceleration of the total vibration of each measuring point under each working condition.

\begin{tabular}{lcccc}
\hline $\begin{array}{l}\text { Measuring } \\
\text { point }\end{array}$ & $\begin{array}{c}\text { Working condition } 1 \\
\left(\mathrm{~m}^{*-2}\right)\end{array}$ & $\begin{array}{c}\text { Working condition } 2 \\
\left(\mathrm{~m} * \mathrm{~s}^{-2}\right)\end{array}$ & $\begin{array}{c}\text { Working condition 3 } \\
\left(\mathrm{m} * \mathrm{~s}^{-2}\right)\end{array}$ & Working condition $4\left(\mathrm{~m} * \mathrm{~s}^{-2}\right)$ \\
\hline 1 & 0.63 & 3.71 & 4.26 & 6.62 \\
2 & 0.78 & 3.23 & 3.47 & 5.18 \\
3 & 0.97 & 2.15 & 5.96 & 7.06 \\
4 & 0.83 & 3.36 & 6.65 & 9.32 \\
\hline
\end{tabular}

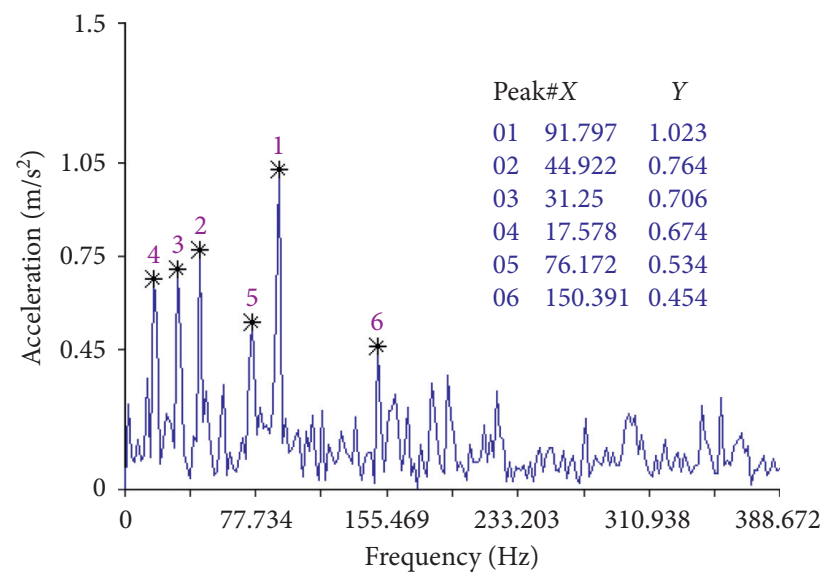

FIGURE 20: FFT of the response of the front left measurement point of the chassis frame.

TABLE 10: Main frequencies and amplitudes under static no-load conditions (components working, small throttle).

\begin{tabular}{|c|c|c|c|c|c|c|c|}
\hline \multirow{2}{*}{$\begin{array}{l}\text { Measuring } \\
\text { point }\end{array}$} & \multirow{2}{*}{$\begin{array}{c}\text { Peak } \\
\text { number }\end{array}$} & \multicolumn{2}{|c|}{$X$-direction } & \multicolumn{2}{|c|}{$Y$-direction } & \multicolumn{2}{|c|}{$Z$-direction } \\
\hline & & Frequency $(\mathrm{Hz})$ & $\begin{array}{l}\text { Amplitude } \\
\left(\mathrm{m} * \mathrm{~s}^{-2}\right)\end{array}$ & $\begin{array}{c}\text { Frequency } \\
(\mathrm{Hz})\end{array}$ & $\begin{array}{l}\text { Amplitude } \\
\left(\mathrm{m} * \mathrm{~s}^{-2}\right)\end{array}$ & $\begin{array}{c}\text { Frequency } \\
(\mathrm{Hz})\end{array}$ & Amplitude $\left(\mathrm{m} * \mathrm{~s}^{-2}\right)$ \\
\hline \multirow{3}{*}{1} & 1 & 48.75 & 0.937 & 48.75 & 1.159 & 24.38 & 0.948 \\
\hline & 2 & 24.38 & 0.823 & 90.63 & 1.088 & 50.63 & 0.438 \\
\hline & 3 & 90.63 & 0.796 & 241.88 & 0.862 & 72.5 & 0.390 \\
\hline \multirow{3}{*}{2} & 1 & 48.13 & 1.504 & 24.38 & 0.430 & 48.13 & 0.914 \\
\hline & 2 & 51.25 & 0.985 & 72.5 & 0.272 & 24.38 & 0.843 \\
\hline & 3 & 24.38 & 0.654 & 96.25 & 0.245 & 51.25 & 0.370 \\
\hline \multirow{3}{*}{3} & 1 & 48.75 & 1.318 & 48.75 & 0.468 & 48.75 & 1.794 \\
\hline & 2 & 24.38 & 0.546 & 24.38 & 0.378 & 24.38 & 0.792 \\
\hline & 3 & 73.13 & 0.490 & 90.63 & 0.264 & 73.13 & 0.399 \\
\hline \multirow{3}{*}{4} & 1 & 48.75 & 1.334 & 73.13 & 0.834 & 24.38 & 1.083 \\
\hline & 2 & 24.38 & 0.567 & 96.88 & 0.828 & 48.75 & 0.818 \\
\hline & 3 & 72.5 & 0.466 & 24.38 & 0.795 & 194.38 & 0.689 \\
\hline
\end{tabular}

condition showed that the chassis frame had the largest amplitude in the $Z$-direction (vertical direction) when it was forced to vibrate, which was the loading direction of the chassis frame relative to each excitation source. In addition, the whole machine had a frequency of 203.61/ $206.54 \mathrm{~Hz}$ that was not available when it was at no load, 
TABLE 11: Main frequencies and amplitudes under static no-load conditions (components working, big throttle).

\begin{tabular}{|c|c|c|c|c|c|c|c|}
\hline \multirow{2}{*}{$\begin{array}{l}\text { Measuring } \\
\text { point }\end{array}$} & \multirow{2}{*}{$\begin{array}{c}\text { Peak } \\
\text { number }\end{array}$} & \multicolumn{2}{|c|}{$X$-direction } & \multicolumn{2}{|c|}{$Y$-direction } & \multicolumn{2}{|c|}{$Z$-direction } \\
\hline & & $\begin{array}{c}\text { Frequency } \\
(\mathrm{Hz})\end{array}$ & $\begin{array}{l}\text { Amplitude } \\
\left(\mathrm{m} * \mathrm{~s}^{-2}\right)\end{array}$ & $\begin{array}{c}\text { Frequency } \\
(\mathrm{Hz})\end{array}$ & $\begin{array}{l}\text { Amplitude } \\
\left(\mathrm{m} * \mathrm{~s}^{-2}\right)\end{array}$ & $\begin{array}{c}\text { Frequency } \\
(\mathrm{Hz})\end{array}$ & Amplitude $\left(\mathrm{m} * \mathrm{~s}^{-2}\right)$ \\
\hline \multirow{3}{*}{1} & 1 & 15 & 13.002 & 15 & 11.79 & 8.13 & 3.570 \\
\hline & 2 & 8.13 & 12.842 & 8.13 & 8.988 & 290 & 3.310 \\
\hline & 3 & 24.38 & 9.832 & 171.25 & 7.67 & 298.13 & 2.518 \\
\hline \multirow{3}{*}{2} & 1 & 91.88 & 1.023 & 91.88 & 2.173 & 6.88 & 1.497 \\
\hline & 2 & 44.92 & 0.764 & 6.88 & 1.021 & 8.13 & 1.120 \\
\hline & 3 & 31.25 & 0.706 & 183.75 & 0.707 & 91.88 & 0.959 \\
\hline \multirow{3}{*}{3} & 1 & 91.88 & 1.399 & 91.88 & 2.087 & 91.88 & 3.816 \\
\hline & 2 & 46.25 & 0.626 & 6.88 & 0.780 & 8.13 & 0.777 \\
\hline & 3 & 6.88 & 0.556 & 20 & 0.649 & 276.25 & 0.772 \\
\hline \multirow{3}{*}{4} & 1 & 91.88 & 2.322 & 91.88 & 2.698 & 179.38 & 2.568 \\
\hline & 2 & 6.88 & 1.159 & 6.88 & 1.353 & 171.25 & 2.252 \\
\hline & 3 & 46.25 & 0.844 & 20 & 0.907 & 163.13 & 2.072 \\
\hline
\end{tabular}

TABLE 12: Main frequency and amplitude under driving conditions (components working, machine walking).

\begin{tabular}{|c|c|c|c|c|c|c|c|}
\hline \multirow{2}{*}{$\begin{array}{l}\text { Measuring } \\
\text { point }\end{array}$} & \multirow{2}{*}{$\begin{array}{c}\text { Peak } \\
\text { number }\end{array}$} & \multicolumn{2}{|c|}{$X$-direction } & \multicolumn{2}{|c|}{$Y$-direction } & \multicolumn{2}{|c|}{$Z$-direction } \\
\hline & & $\begin{array}{c}\text { Frequency } \\
(\mathrm{Hz})\end{array}$ & $\begin{array}{c}\text { Amplitude } \\
\left(\mathrm{m}^{*} \mathrm{~s}^{-2}\right)\end{array}$ & $\begin{array}{c}\text { Frequency } \\
(\mathrm{Hz})\end{array}$ & $\begin{array}{c}\text { Amplitude } \\
\left(\mathrm{m}^{*} \mathrm{~s}^{-2}\right)\end{array}$ & $\begin{array}{c}\text { Frequency } \\
(\mathrm{Hz})\end{array}$ & Amplitude $\left(\mathrm{m}^{*} \mathrm{~s}^{-2}\right)$ \\
\hline \multirow{3}{*}{1} & 1 & 180.66 & 1.230 & 158.20 & 2.551 & 15.14 & 0.861 \\
\hline & 2 & 78.13 & 1.063 & 203.61 & 1.328 & 7.32 & 0.809 \\
\hline & 3 & 90.33 & 0.823 & 174.81 & 0.959 & 206.54 & 0.783 \\
\hline \multirow{3}{*}{2} & 1 & 180.66 & 1.214 & 271.97 & 1.082 & 90.33 & 2.257 \\
\hline & 2 & 90.82 & 1.168 & 257.32 & 1.025 & 232.91 & 1.243 \\
\hline & 3 & 78.13 & 1.035 & 181.15 & 0.873 & 205.57 & 1.087 \\
\hline \multirow{3}{*}{3} & 1 & 181.15 & 2.227 & 271.48 & 0.926 & 90.82 & 7.632 \\
\hline & 2 & 90.82 & 1.691 & 7.81 & 0.914 & 181.15 & 3.903 \\
\hline & 3 & 7.81 & 0.751 & 204.10 & 0.712 & 271.97 & 1.262 \\
\hline \multirow{3}{*}{4} & 1 & 181.15 & 0.838 & 204.10 & 4.724 & 181.15 & 6.027 \\
\hline & 2 & 90.33 & 0.772 & 158.69 & 3.508 & 203.61 & 3.433 \\
\hline & 3 & 45.41 & 0.651 & 232.42 & 3.273 & 233.40 & 2.473 \\
\hline
\end{tabular}

and there were many side frequencies near it which showed that these two frequencies may be the resonance frequency of a structure.

\section{Conclusions}

(1) According to the action mode and force of the existing working parts of combine harvester on the chassis frame, it was statically calculated. The results showed that when the combine was fully loaded, the maximum bending moment of all the load beams appeared on one of the load beams of the grain box. The maximum bending moment was $M_{\max }=2298.08 \mathrm{~N} / \mathrm{m}$, and it was located at a cross section of the load beam with a distance of $1.61 \mathrm{~m}$ from the left end boundary. In addition, stress check was carried out on the dangerous position. The stress value at this point was the maximum stress point of the entire chassis frame, and its maximum normal stress $\sigma_{\max }=99.1 \mathrm{MPa}<[\sigma]$, which met the requirements of Q235 material, indicating that the designed chassis had the ability to carry the main working components of the entire machine.
(2) The first 6 natural frequencies of the chassis frame were within the working frequency range of multiple vibration sources on the combine harvester, and there was more overlap between the $20-25 \mathrm{~Hz}$ and $40-45 \mathrm{~Hz}$ intervals. It may cause complex vibration coupling and resonance, resulting in severe vibration of the fuselage when the whole machine was working. Furthermore, it would cause fatigue damage to key components and greatly reduce the life of the combine harvester.

(3) The vibration of the chassis frame was the smallest when the engine was working only. When the working components of the whole machine were working, the vibration of the chassis frame at the rear right was the most intense. Considering the fact that there was still alternating excitation force generated by threshing in the threshing drum during actual work, the support frame at this position should be further strengthened to improve the reliability of the long-term operation of the chassis frame, thereby improving the working reliability of the whole machine. 
(4) When the whole machine was moving in the field and all parts were working, the vibration amplitude of the chassis frame was the largest. The horizontal vibration of the threshing drum, the reciprocating motion generated by the vibrating screen, and the vertical vibration generated by the engine were the main vibration sources of the combine harvester in the three directions of $X, Y$, and $Z$. Besides, each working condition showed that the chassis frame had the largest amplitude in the $Z$-direction (vertical direction) when it was forced to vibrate, and this direction was the loading direction of the chassis frame relative to each excitation source.

\section{Data Availability}

The data used to support the findings of this study are available from the corresponding author upon request.

\section{Conflicts of Interest}

The authors declare that they have no conflicts of interest.

\section{Acknowledgments}

This research work was supported by the Natural Science Foundation of Jiangsu Province (BK20170553), National Natural Science Foundation of China (51705212), Jiangsu Province "Six Talents Peak" High-level Talent Project (GDZB-085), Open Fund of Jiangsu Key Laboratory of Agricultural Equipment and Intelligent High Technology (JNZ201912), and Jiangsu Province Postgraduate Research and Innovation Project (KYCX20_3086).

\section{References}

[1] A. M. Parker, A. Proctor, R. L. Eason, and V. Jain, "Effects of rice harvest moisture on kernel damage and milled rice surface free fatty acid levels," Journal of Food Science, vol. 72, pp. 10-15, 2007.

[2] Z. Tang, Y. Li, X. Li, and T. Xu, "Structural damage modes for rice stalks undergoing threshing," Biosystems Engineering, vol. 186, pp. 323-336, 2019.

[3] Z. Tang, M. L. Wang, H. T. Zhang, Y. P. Zhou, and Y. Li, "Variation and modal characteristic of tangential threshing cylinder undergoing threshing dynamics," Mathematical Problems in Engineering, vol. 2020, Article ID 1723893, 15 pages, 2020.

[4] Z. Tang, H. T. Zhang, H. Zhang et al., "Developments of crawler steering gearbox for combine harvester straight forward and steering in situ," International Journal of Agricultural and Biological Engineering, vol. 13, no. 1, pp. 120-126, 2020.

[5] R. Prasad, Y. S. Shivay, and D. Kumar, "Current status, challenges, and opportunities in rice production," Rice Production Worldwide, vol. 2, pp. 1-32, 2017.

[6] Z. Tang, X. Li, X. Liu, H. Ren, and B. Zhang, "Dynamic balance method for grading the chain drive double threshing drum of a combine harvester," Applied Sciences, vol. 10, no. 3, pp. 1026-1046, 2020.
[7] Z. W. Liang, Y. M. Li, and L. Z. Xu, "Grain sieve loss fuzzy control system in rice combine harvesters," Applied Sciences, vol. 9, no. 1, 2018.

[8] P. Li and H. Xu, "Braking efficiency and stability of chassis braking system of combine harvester: the theoretical derivation and virtual prototype simulation," Mathematical Problems in Engineering, vol. 2019, Article ID 6713231, 18 pages, 2019.

[9] Z. Tang, X. Y. Li, X. D. Chen, and Y. Chen, "Design of negative pressure spiral feeding device for tangential and longitudinal axial intersection of combine harvester," Advances in Materials Science and Engineering, vol. 2019, Article ID 1647230, 12 pages, 2019.

[10] Z. Tang, H. T. Zhang, and Y. P. Zhou, "Unbalanced vibration identification of tangential threshing cylinder induced by rice threshing process," Shock and Vibration, vol. 2018, Article ID 4708730, 14 pages, 2018.

[11] C. L. Li, S. C. Yin, X. P. Jin, E. R. Mao, X. H. Lou, and Z. H. Song, "Rapid design of powertrain in wheeled combine harvester chassis based on knowledge," Applied Mechanics and Materials, vol. 472, pp. 516-521, 2014.

[12] D. F. Hu and Y. P. Du, "Strength analysis of corn combine harvester chassis," Applied Mechanics and Materials, vol. 644-650, pp. 489-492, 2014.

[13] P. Vijaykumar and R. I. Patel, "Structural analysis of automotive chassis frame and design modification for weight reduction," International Journal of Engineering Research and Technology, vol. 1, no. 3, 2012.

[14] N. S. Nagaraju, M. V. Kumar, and U. Koteswarao, "Modeling and analysis of an innova car chassis frame by varying cross section," International Journal of Engineering Research and Technology, vol. 2, pp. 1-12, 2013.

[15] Z. Tang, H. Ren, X. Li, X. Liu, and B. Zhang, "Structure design and bearing capacity analysis for crawler chassis of rice combine harvester," Complexity, vol. 2020, Article ID 7610767, 15 pages, 2020.

[16] Z. Chen, T. Wang, F. Gu, and R. Zhang, "Characterizing the dynamic response of a chassis frame in a heavy-duty dump vehicle based on an improved stochastic system identification," Shock and Vibration, vol. 2015, Article ID 374083, 15 pages, 2015.

[17] Y. Jiang, Y. Liao, C. Qin, Z. Guan, and Q. Liao, "Vibration analysis and improvement for frame of 4SY-2.9 typed rape windrower," Transactions of the Chinese Society of Agricultural Engineering, vol. 33, pp. 53-60, 2017.

[18] S. Ganesan and K. Panneerselvam, "Vibration reduction in conventional vehicles by increasing the stiffness on the chassis frame," Journal of Engineering and Applied Science, vol. 10, pp. 3384-3390, 2015.

[19] T. T. Yao and Y. Zheng, "Finite element analysis of stress, deformation and modal of head cover in axial-flow hydroturbine," Journal of Drainage and Irrigation Machinery Engineering, vol. 38, no. 1, pp. 39-44, 2020.

[20] A. Xue, Z. G. Li, Z. S. Manuela, T. M. Fideline, and Y. G. Yang, "Characterization of textural failure mechanics of strawberry fruit," Journal of Food Engineering, vol. 282, Article ID 110016, 2020.

[21] Z. N. Lai, S. Yang, and P. Wu, "Speed-throttling combined optimization for high reliability in parallel centrifugal pump system," Journal of Drainage and Irrigation Machinery Engineering, vol. 36, pp. 1205-1210, 2018.

[22] Z. Tang, H. T. Zhang, Y. P. Zhou, and Y. Li, "Mutual interference and coupling response of multicylinder vibration 
among combine harvester co-frame," Shock and Vibration, vol. 2019, Article ID 1584391, 14 pages, 2019.

[23] I. Maciejewski, T. Krzyzynski, and H. Meyer, "Modeling and vibration control of an active horizontal seat suspension with pneumatic muscles," Journal of Vibration and Control, vol. 24, no. 24, pp. 5938-5950, 2018.

[24] D. Huang, S. Zhou, and G. Litak, "Analytical analysis of the vibrational tristable energy harvester with a $\mathrm{RL}$ resonant circuit," Nonlinear Dynamics, vol. 97, no. 1, pp. 663-677, 2019.

[25] Y. Fang and T. Zhang, "Modeling and analysis of electric powertrain NVH under multi-source dynamic excitation," SAE Technical Paper, vol. 1, p. 2870, 2014.

[26] Z. Y. Xie, Q. D. Zhou, and Y. C. Pan, "Simulation and tests for vibration of structures under multi-point complex loads," Journal of Vibration and Shock, vol. 37, pp. 166-174, 2018.

[27] S. Chen, Y. Zhou, Z. Tang, and S. Lu, "Modal vibration response of rice combine harvester frame under multi-source excitation," Biosystems Engineering, vol. 194, pp. 177-195, 2020.

[28] K. Lee, "Large deflections of cantilever beams of non-linear elastic material under a combined loading," International Journal of Non-linear Mechanics, vol. 37, no. 3, pp. 439-443, 2002.

[29] S. A. Emam, M. A. Eltaher, M. E. Khater, and W. S. Abdalla, "Postbuckling and free vibration of multilayer imperfect nanobeams under a pre-stress load," Applied Sciences, vol. 8, no. 11, p. 2238, 2018.

[30] J. T. Oden and J. N. Reddy, Variational Methods in Theoretical Mechanics, Springer-Verlag, Berlin, Germany, 1976.

[31] X. H. Wang, Y. Li, H. L. Liu, K. Wang, S. H. Wang, and Y. Wang, "Influence of geometrical parameters of vibration damping raft on vibration characteristics of marine centrifugal pump," Journal of Drainage and Irrigation Machinery Engineering, vol. 37, no. 11, pp. 929-935, 2019.

[32] D. Cao, S. Rakheja, and C. Y. Su, "Dynamic analyses of heavy vehicle with pitch-interconnected suspensions," International Journal of Heavy Vehicle Systems, vol. 15, no. 2-4, pp. 272308, 2008. 